\title{
Impact of age of first exposure to Plasmodium falciparum on antibody responses to malaria in children: a randomized, controlled trial in Mozambique
}

Augusto J Nhabomba ${ }^{1 *}$, Caterina Guinovart ${ }^{1,2,3}$, Alfons Jiménez ${ }^{2,3}$, Maria N Manaca', Llorenç Quintó ${ }^{2,3}$, Pau Cisteró ${ }^{2}$, Ruth Aguilar ${ }^{1,2,3}$, Arnoldo Barbosa ${ }^{1}$, Mauricio H Rodríguez ${ }^{1}$, Quique Bassat ${ }^{1,2,3}$, John J Aponte ${ }^{1,2,3}$, Alfredo Mayor ${ }^{1,2,3}$, Chetan E Chitnis ${ }^{4}$, Pedro L Alonso ${ }^{1,2,3}$ and Carlota Dobaño $0^{1,2,3^{*}}$

\begin{abstract}
Background: The impact of the age of first Plasmodium falciparum infection on the rate of acquisition of immunity to malaria and on the immune correlates of protection has proven difficult to elucidate. A randomized, double-blind, placebo-controlled trial using monthly chemoprophylaxis with sulphadoxine-pyrimethamine plus artesunate was conducted to modify the age of first $P$. falciparum erythrocytic exposure in infancy and assess antibodies and malaria risk over two years.
\end{abstract}

Methods: Participants $(n=349)$ were enrolled at birth to one of three groups: late exposure, early exposure and control group, and were followed up for malaria morbidity and immunological analyses at birth, 2.5, 5.5, 10.5, 15 and 24 months of age. Total IgG, IgG subclasses and IgM responses to MSP-1 ${ }_{19}$, AMA-1, and EBA-175 were measured by ELISA, and IgG against variant antigens on the surface of infected erythrocytes by flow cytometry. Factors affecting antibody responses in relation to chemoprophylaxis and malaria incidence were evaluated.

Results: Generally, antibody responses did not vary significantly between exposure groups except for levels of IgM to EBA-175, and seropositivity of IgG1 and IgG3 to MSP-1 19 . Previous and current malaria infections were strongly associated with increased IgG against MSP-1 ${ }_{19}$, EBA-175 and AMA-1 $(p<0.0001)$. After adjusting for exposure, only higher levels of anti-EBA-175 lgG were significantly associated with reduced clinical malaria incidence (IRR 0.67, $\mathrm{p}=0.0178$ ).

Conclusions: Overall, the age of first $P$. falciparum infection did not influence the magnitude and breadth of IgG responses, but previous exposure was critical for antibody acquisition. IgG responses to EBA-175 were the strongest correlate of protection against clinical malaria.

Trial registration: ClinicalTrials.gov: NCT00231452.

Keywords: Malaria, Antibodies, Acquired immunity, Age, Exposure, Plasmodium falciparum

\footnotetext{
*Correspondence: augusto.nhabomba@gmail.com; CDOBANO@clinic.ub.es

${ }^{1}$ Centro de Investigação em Saúde de Manhiça (CISM), Maputo, Mozambique

${ }^{2}$ Barcelona Centre for International Health Research (CRESIB, Hospital Clínic -

Universitat de Barcelona), Barcelona, Catalonia, Spain

Full list of author information is available at the end of the article
} 


\section{Background}

Malaria is among the leading causes of morbidity and death in children, despite being a preventable disease. The World Health Organization estimates that 219 million cases and 660,000 deaths occurred in 2010, with approximately 81 and $91 \%$, respectively, being in subSaharan Africa [1]. Under similar levels of exposure to Plasmodium falciparum different individuals experience different outcomes; while some may die of severe malaria others may experience mild disease to asymptomatic infection [2,3]. However, immunity to malaria is poorly understood. The rate of its development is thought to be associated with transmission intensity; it is both species and stage-specific and is rarely sterile [4]. In endemic areas, the acquisition of partial immunity to severe forms of the disease is observed relatively early in life [2], whereas immunity to parasitaemia and mild clinical malaria appear to take longer to develop and may require repeated parasite exposure for maintenance $[5,6]$. Human host genetics, parasite genetic variability and parasite-induced immunosuppression also influence the acquisition of immunity $[7,8]$.

In people living in endemic areas, malaria infection induces strong humoral immune responses, involving production of predominantly immunoglobulin (Ig) $\mathrm{M}$ and IgG $[9,10]$. Cytophilic IgG isotypes, IgG1 and IgG3 are known to cooperate with monocytes to inhibit parasite growth in vitro by promoting phagocytosis of $P$. falciparum-infected erythrocytes $[3,9,11,12]$. Passive transfer of IgG from immune donors to non-immune children demonstrated that antibodies can be protective by reducing parasitaemia and clinical disease [13]. Parasite growth inhibition by plasma has been demonstrated in vitro for some blood stage antigens that are candidates for malaria vaccines. First, the recombinant $62 \mathrm{kDa}$ apical membrane antigen-1 (AMA-1), involved in the re-orientation of merozoites prior to invasion of the erythrocyte [14]; second, the erythrocyte binding antigen (EBA-175), a $175 \mathrm{kDa}$ protein assumed to bind glycophorin A (GpA) during invasion [14,15]; and, third, the $195 \mathrm{kDa}$ merozoite surface protein-1 (MSP-1 19$)$, the most abundant merozoite surface protein, thought to be involved in the initial attachment of the merozoite to the erythrocyte surface [14]. Sero-epidemiological studies in populations of endemic areas have shown some evidences of the role of antibodies to these antigens in protecting against malaria [16].

Variant surface antigens (VSA) expressed on the parasitized erythrocyte membrane are thought to induce protective responses to $P$. falciparum as well [17]. The predominant VSA are encoded by $\sim 60$ var genes per parasite genome [18]. The gene product, called P. falciparum erythrocyte membrane protein 1 (PfEMP-1), is highly variant and equipped with several binding sites mediating adhesion of infected erythrocytes to vascular endothelium of capillaries and post-capillary venules thus avoiding destruction in the spleen [18-21]. Following acute disease, children develop specific immune responses to the repertoire of VSAs of the parasites that cause the infection [5,6]. Anti-VSA antibodies carried by the host at the time of disease impose a selection pressure on the repertoire of VSAs expressed during an infection [22].

Longitudinal studies in Indonesia [23] and Tanzania $[24,25]$ suggested that a more mature immune system should acquire immunity against malaria more efficiently than a developing immune system, and that the age of first exposure to the parasite might influence the development of immunity. However, the exact effect of age of first exposure on the development of immunity was not clear, and this is critical for preventing children from avoidable life-threatening infections. Following conclusions from these studies, it was hypothesized that exposure to $P$. falciparum during the first six months of life was not relevant for acquisition of immunity, whereas exposure in the second six months could be critical for acquisition of immunity, and conducted a clinical trial to test this. The age of first exposure to $P$. falciparum blood stage infection was controlled by chemoprophylaxis with sulphadoxine-pyrimethamine (SP) plus artesunate (AS) during different periods of the first year of life in Mozambican children who were then followed up to 24 months for clinical malaria [26]. The conclusion of this trial was that after significantly interfering with exposure during the first year of life, the age of first exposure to malaria did not seem to affect the incidence of clinical malaria in the second year. However it remains to be established whether the intervention affected the acquisition of antibody responses to antigens considered to be targets of blood stage immunity.

A detailed assessment of antibody responses to MSP$1_{19}$, AMA-1, EBA-175 and VSA antigens was conducted in the children participating in the clinical trial during their first two years of life. Risk factors affecting antibody levels were examined at five cross sectional visits and upon P. falciparum infection and convalescence, and the association between the magnitude and breadth of antibody response and subsequent incidence of malaria.

\section{Methods}

\section{Study site and population}

The study was conducted in the District of Manhiça (Maputo Province) in Southern Mozambique, in the neighbourhoods of Maragra and Maciana in the town of Manhiça. Characteristics of the area have been described elsewhere [27]. Briefly, transmission of P. falciparum malaria is perennial with two well-demarked seasons, a dry season (May-October) and a rainy season (NovemberApril). The entomological inoculation rate estimated in 
2002 was of 38 infective bites/person/year [28]. A demographic surveillance system (DSS) that has been in place since mid-1996 continuously monitored the residents. Inhabitants are mostly subsistence farmers living in compounds separated by garden plots and grazing land [26].

\section{Study design}

The study was a double-blind, randomized, placebocontrolled trial, described in detail elsewhere [26]. Briefly, $391 \mathrm{HIV}$-negative pregnant women were invited to have their infants participate in the trial. Forty-five newborns were excluded from the study: ten withdrawals, eight stillbirths, three deaths before inclusion, one unknown and twenty three who did not meet inclusion criteria (birth weight $<2 \mathrm{~kg}$, same gender twins, congenital malformations or birth asphyxia). A total of 349 newborns and their mothers were enrolled in the study and 287 children completed the two-year follow up [26]. Eligible newborns were randomized to one of three chemoprophylactic groups. The late exposure group received monthly chemoprophylaxis with SP + AS from 2.5 until 4.5 months of age and placebo from 5.5 to 9.5 months of age. The early exposure group received placebo from 2.5 until 4.5 months of age and monthly chemoprophylaxis from 5.5 to 9.5 months of age. The control group received monthly placebo from 2.5 to 9.5 months of age. Given the relatively long half-life of SP, it was assumed that the chemoprophylactic effect lasted for at least one month after each administration. One-and-a-half $\mathrm{mL}$ of capillary blood was collected for serological and parasitological determinations at crosssectional visits (2.5, 5.5, 10.5, 15 and 24 months). Capillary blood from the first acute malaria infection and at convalescence, one month after the first malaria episode, was also collected for serological and parasitological analyses.

\section{Ethical clearance}

Approval for the study was obtained from the National Mozambican Ethics Review Committee (Ref 05/CNBS/05) and the Hospital Clínic of Barcelona Ethics Review Committee. Children were enrolled in the study after their mothers gave a written informed consent.

\section{Parasite isolates, in vitro culture and measurement of IgG against VSA}

In previous work by the same group, a panel of parasite isolates (Moz2, R29, 3D7, ItG and EB8) was tested for immunogenicity. The laboratory line (R29) was found to be the most immunogenic in the study area $[29,30]$. Stocks of ring stage at 3\% parasitaemia were prepared from R29 P. falciparum parasite in vitro cultures. Parasites were cryopreserved by adding 1.7 volumes of glycerolyte dropwise and at a continuous agitation, and then kept at $-80^{\circ} \mathrm{C}$. For recovery, parasite aliquots were thawed using two sodium chloride thawing solutions $(0.2 \mathrm{~V}$ of $12 \% \mathrm{NaCl}$ and $10 \mathrm{~V}$ of $1.6 \%$; and washed with RPMI incomplete media) following the protocol described elsewhere [6]. Parasite culture to late trophozoite was done using standard protocols [31].

The protocol for quantifying IgG against $P$. falciparum VSA has been described elsewhere [6]. Briefly, $95 \mu \mathrm{L}$ of trophozoite-infected erythrocytes (T-iE) at $1 \%$ parasitaemia were sequentially exposed to $5 \mu \mathrm{L}$ of plasma, $0.5 \mu \mathrm{L}$ of polyclonal rabbit anti-human IgG (Dako, Glostrup, Denmark) and $0.1 \mu \mathrm{L}$ of a goat anti-rabbit IgG antibody (Invitrogen, Molecular Probes, Carlsbad, USA) together with $0.1 \mu \mathrm{L}$ of ethidium bromide (Applichen UN2810 1\%). Samples were washed three times with PBS-1\% BSA after each step of incubation with antibodies. Four serial dilutions $(1 / 20,1 / 40,1 / 80,1 / 160)$ of a pool of positive control plasmas (from healthy adults with life-long continuous exposure to P. falciparum) and one dilution $(1 / 20)$ of five negative control plasmas (from adults without a history of contact with malaria parasites) were included in each plate. Samples were then acquired in a four-colour FACSCalibur (Becton Dickinson, USA) using CellQuest 3.3 software. Up to 1,000 T-iE (or ethidium bromide positive events) were counted per sample, and the geometric means (GM) of the fluorescence intensities were calculated.

\section{Enzyme-linked immunosorbent assay (ELISA)}

All plasma samples were assayed for total IgG, isotypes (IgG1, IgG2, IgG3, IgG4) and IgM against the recombinant proteins MSP- $_{19}$ (19-kDa C-terminal fragment, 3D7 strain), AMA-1 (ectodomain, 3D7 strain), and EBA-175 (region II, fragment I, CAMP strain) from the ICGEB (New Delhi, India) [32]. Ninety-six-well plates were coated with $200 \mathrm{ng}$ per well of antigen diluted in $0.05 \mathrm{M}$ carbonate-bicarbonate buffer and incubated overnight at $4^{\circ} \mathrm{C}$. Next day, plates were blocked with $2 \%$ bovine serum albumin in PBS-Tween for eight hours at $4^{\circ} \mathrm{C}$. Then, plasma samples (dilution 1/200) were added in duplicates along with a positive control (a pool of plasmas from eight adults with lifelong exposure to malaria in the dilutions: $1 / 400,1 / 800,1 / 1,600$ and $1 / 3,200$ ), nine negative controls (plasmas from nine non-exposed adults, diluted 1/400) and two myeloma controls (for conjugated antibodies) $1 \mu \mathrm{g} / \mathrm{ml}$ and $0.5 \mu \mathrm{g} / \mathrm{ml}$. All incubations were followed by three washings with $0.05 \%$ Tween $20+$ BSA $0.25 \%$ in PBS. After one-hour incubation with $100 \mu \mathrm{L}$ of peroxidase-conjugated rabbit anti-human $\operatorname{IgG}(1 / 8,000)$, IgM $(1 / 3,000)$ (DakoCytomation) and sheep anti-human IgG1 (1/6,000), IgG2 (1/1,500), IgG3 (1/1,500), IgG4 $(1 / 3,000)$ isotypes (Binding site, UK) secondary antibodies diluted in wash buffer, respectively, $100 \mu \mathrm{L}$ of citric acid $0.243 \mathrm{M}+\mathrm{Na}_{2} \mathrm{HPO}_{4} 0.512 \mathrm{M}+1 \mathrm{mg} / \mathrm{ml}$ of o-phenylenediamine chromogen (Sigma, St Louis, MO, 
USA) with $0.012 \% \mathrm{H}_{2} \mathrm{O}_{2}$ substrate were added per well for $5 \mathrm{~min}$, and the colorimetric reaction was stopped with $25 \mu \mathrm{L}$ of $3 \mathrm{M} \mathrm{H}_{2} \mathrm{SO}_{4}$. The specific reactivities of plasma samples were obtained as optical density (OD) values (absorbance measured at $492 \mathrm{~nm}$ normalized against a positive control run in every experiment). In addition, antibody levels were categorized using a cutoff OD value (the arithmetic mean of negative controls plus three standard deviations) for statistical analyses.

\section{Parasitaemia}

Plasmodium falciparum infections were diagnosed and quantified by microscopy at 2.5 and 24 months of age, and in non-programmed visits whenever a child attended the hospital with fever or history of fever in the preceding 24 hours. Thick and thin blood films were Giemsa-stained and read as previously described [26]. Cases with submicroscopic parasitaemia were assessed by quantitative real time PCR (qPCR) performed from filter paper blood spots at birth (from cord blood), 2.5 and 24 months of age. DNA for qPCR analysis was extracted using the QIAamp DNA mini kit (Qiagen). The method used for qPCR was a minor modification of a protocol described elsewhere [33]. Briefly, the qPCR amplified the multicopy $18 \mathrm{~S}$ ribosomal RNA gene of $P$. falciparum. The probe used was labelled with 6-carboxy-flourescein. A standard curve was produced using known concentrations of 3D7 strain P. falciparum parasites in parasite culture. Importing this curve into subsequent qPCR runs achieved quantification of parasitaemia with an ABI Prism 7500 apparatus (Applied Biosystems).

\section{Definitions and statistical methods}

Clinical malaria was defined as axillary temperature $\geq 37.5^{\circ} \mathrm{C}$ or reported fever in the preceding 24 hours, plus positive parasitaemia by microscopy. For anti-VSAs antibodies the sample fluorescence intensity was defined as the difference between the GM of the fluorescence emitted by the T-iE and the GM of the fluorescence emitted by the non-infected erythrocytes. Antibody values for ELISA (ELISA - normalized OD values for total IgG, IgG isotypes and IgM) were logarithmically transformed and averaged within the groups and presented as GM plus 95\% confidence intervals (CI). Distribution of antibody responses to each antigen at each cross-sectional visit, acute malaria and convalescence, are presented as weighted scatter plots. Differences in antibody prevalence (percentage of positive responders) between treatment groups at different time points were estimated by Chi-square and Fisher's exact test, as appropriate, and differences in continuous antibody values among treatment groups were evaluated by ANOVA, evaluated using a likelihood ratio test and a global p-value was used for significance. Breadth of antibodies at the cross- sectional visits was defined as the number of antigens with positive IgG or IgM antibodies responses as defined by the categories above. Mixed-effects linear regression models with a random-intercept at the subject level were used to analyse factors independently associated with antibody levels at the cross-sectional visits, and the variables used to estimate models were: intervention group, age, season (dry/rainy), neighbourhood (grouped in 10 geographical categories), gender, previous infection, current infection, low birth weight, weight for age score, maternal peripheral infection, placental infection and inflammation, parity, maternal age, maternal anaemia, congenital infection (parasites in cord blood by qPCR), use of insecticide-treated nets (ITN) and documented indoor residual spraying (IRS) in the household. Selection of the variables for the multivariable model was done through a forward-stepwise procedure, where the criterion for including a variable to the model was $\mathrm{p}$-value $\leq 0.05$ from the likelihood ratio test. In addition, mixed-effects linear regression models were used to analyse the effect on antibody responses of the following variables selected for the highest biological plausibility to influence Ig levels: intervention group, age, season, neighbourhood, previous infection, current infection, placental infection and inflammation, congenital infection and low birth weight. Antibody levels and breadth of response at the cross-sectional visits in relation to incidence of malaria were assessed by negative binomial regression models. First, the control group (no treatment) was evaluated in two risk intervals from 2.5 to 12 months and from 2.5 to 24 months. Second, all treatment groups were assessed in three risk intervals: from 5.5 to 24 months, from 10.5 to 24 months and from 15 to 24 months. The strength of the association between antibody levels or breadth and malaria risk was assessed first unadjusted and second after adjusting by treatment, age, season, neighbourhood, current infection, previous infection, maternal infection, congenital infection, placental inflammation, ITN use and IRS. Statistical significance was defined at $\mathrm{P}<0.05$. Crude $\mathrm{p}$ values reported in this exploratory study were not adjusted for multiple comparisons and were interpreted for internal coherence, consistency of results and biological plausibility. Data analysis was performed using STATA 11 (StataCorp. 2007. Stata Statistical Software: Release 10. College Station, TX: StataCorp LP).

\section{Results}

\section{Comparison of antibody responses between} chemoprophylaxis groups

The magnitude of antibody responses was compared between study groups during the intervention period (first year) and after the intervention period (second year). Antibody responses to $P$. falciparum did not differ 
significantly between intervention arms at most study visits (cross-sectionals, first clinical acute episode or convalescence) for the majority of serological markers evaluated (Figures 1 and 2). Overall, results of linear regression analyses were similar after adjusting for previous episodes of clinical malaria.

In the first year of life, significant differences according to the intervention group were only observed in some antibody markers at month 10.5. Levels of IgM were higher in the late exposure and control groups, who were exposed to infection between months 5.5 and 10.5, compared to the early exposure group, who were under chemoprophylaxis during that period (GM, 95\% CI; EBA-175: $0.45,0.42-0.49$ and $0.49,0.45-0.53$ vs 0.42 , $0.38-0.46$, respectively, $\mathrm{p}=0.0469$; AMA-1: $0.40,0.37$ 0.43 and $0.40,0.37-0.42$ vs $0.35,0.32-0.39, \mathrm{p}=0.0543$; MSP- $1_{19}: 0.43,0.39-0.47$ and $0.46,0.41-0.52$ vs 0.40 , $0.36-0.43, \mathrm{p}=0.0885$ ) (Figure 1). Antibody levels did not differ between groups at month 5.5 following chemoprophylaxis in the late exposure group (administered at months 2.5 to 4.5). Geometric means and 95\% CI for control, late exposure and early exposure groups were: MSP-1 $_{19}$ : 0.37, 0.34-041; 0.35, 0.31-0.39 and 0.37, 0.33$0.41, \mathrm{p}=0.6894 ;$ AMA- $1: 0.38,0.34-0.42 ; 0.33,0.31-0.37$ and 0.37, 0.34-0.41, $\mathrm{p}=0.1320$; EBA-175: 0.39, 0.35-0.42; $0.35,032-0.38$ and $0.36,0.33-0.39 \mathrm{p}=0.2106$, respectively.

In contrast, IgG levels did not significantly vary after chemoprophylaxis and thus there was no evidence for supporting differences in IgG levels between the three exposure groups at the cross-sectional visits (Figures 2 and 3). This was observed when comparing crude GM antibody levels, antibody prevalences, and also adjusted for previous clinical malaria episodes. The only instances where there were significant differences in IgG responses between intervention groups was also in the direction of lower IgG levels after drug administration, and this was manifested for cytophilic IgGs against MSP- $1_{19}$ at month 10.5. Specifically, the prevalence of positive IgG1 responses was lower in the early exposure group compared to the late exposure and control groups (13 vs 28\%, 28\%, respectively; $\mathrm{Chi}^{2} \mathrm{p}=0.0248$ ), and similarly for levels of IgG3 (linear regression model unadjusted $\mathrm{p}=0.0284$, adjusted for prior malaria $\mathrm{p}=0.0343$ ). Non-cytophilic antibodies (IgG2 and IgG4) yielded consistently low level responses and are not reported here.

In the second year, no significant differences in antibody levels were detected overall according to intervention group. However, children with prior malaria exposure (documented previous episodes of parasitologically confirmed clinical malaria) who had received SP + AS chemoprophylaxis any time during year 1 (early exposure and late exposure groups) had higher IgG to MSP-1 $1_{19}$, EBA175 and AMA-1 at 15 and 24 months of age than Control children who had been under continuous exposure to
P. falciparum (Figures 3, 4 and 5). Regarding IgM responses, a higher seroprevalence for the early exposure group compared to the late exposure and control groups was also observed at age 24 months (MSP- $1_{19}: 13$ vs $7 \%$ and 3\%, respectively, $\mathrm{p}=0.038$; EBA-175: 6 vs 4\% and 0\%, $\mathrm{p}=0.032$; AMA-1: 26 vs $18 \%$ and 15\%, $\mathrm{p}=0.195$ Chi $^{2}$ test).

There were no statistically significant differences in IgG responses to VSA among the three groups at any of the sampling visits (Additional file 1).

\section{Analysis of factors affecting the magnitude of antibody responses}

Age was the only factor significantly affecting the level of all antibodies against all antigens studied, even after adjusting for all the covariates (Table $1, \mathrm{p}<0.0001$ and Additional file 2). IgM levels significantly increased with age (Figure 1). Overall, IgG levels were higher at month 2.5 presumably because of the antibodies acquired passively from the mother, then significantly decayed from 5.5 to 10.5 months, before a gradual increase onwards, depending on the antigen (Figure 2). Previous and current infections significantly increased IgG antibodies and isotypes against the majority of the studied antigens ( $\mathrm{p}$ values between $<0.0389$ and 0.0001 ). Dry season was significantly associated with reduced levels of IgG to MSP$1_{19}$ and IgG1 to AMA-1 and EBA-175, and with higher levels of IgG3 to EBA-175 (Table 1, Additional file 2). Neighbourhood, reflecting heterogeneity in exposure to malaria infection, influenced levels of IgG, IgG1 and IgG3 mainly against MSP- $1_{19}$ and AMA-1 (Table 1, Additional file 2). Particular neighbourhoods were consistently associated with higher antibody responses while other were neutral (Additional files 3 and 4). Other factors examined related to in utero parasite exposure such as placental infection or inflammation, congenital infection or low birth weight did not always affect all antibody levels significantly (Table 1, Additional file 2), but overall, parasite exposure variables that affected the magnitude of antibodies were similar between the stepwise and multilevel analyses. Gender and parity did not have an effect on any of the antibodies studied.

\section{Antibody responses during a first acute clinical malaria episode and at convalescence}

Antibody levels significantly varied following a first episode of clinical malaria compared to the levels measured at the preceding cross-sectional visits (Table 2). The most marked increases were observed from acute disease to convalescence for AMA-1 and MSP- $1_{19}$ responses, and to a lesser extent for EBA-175 responses. The pattern of cytophilic IgG1 and IgG3 responses before, during and after a clinical malaria episode is shown in Figure 6. 

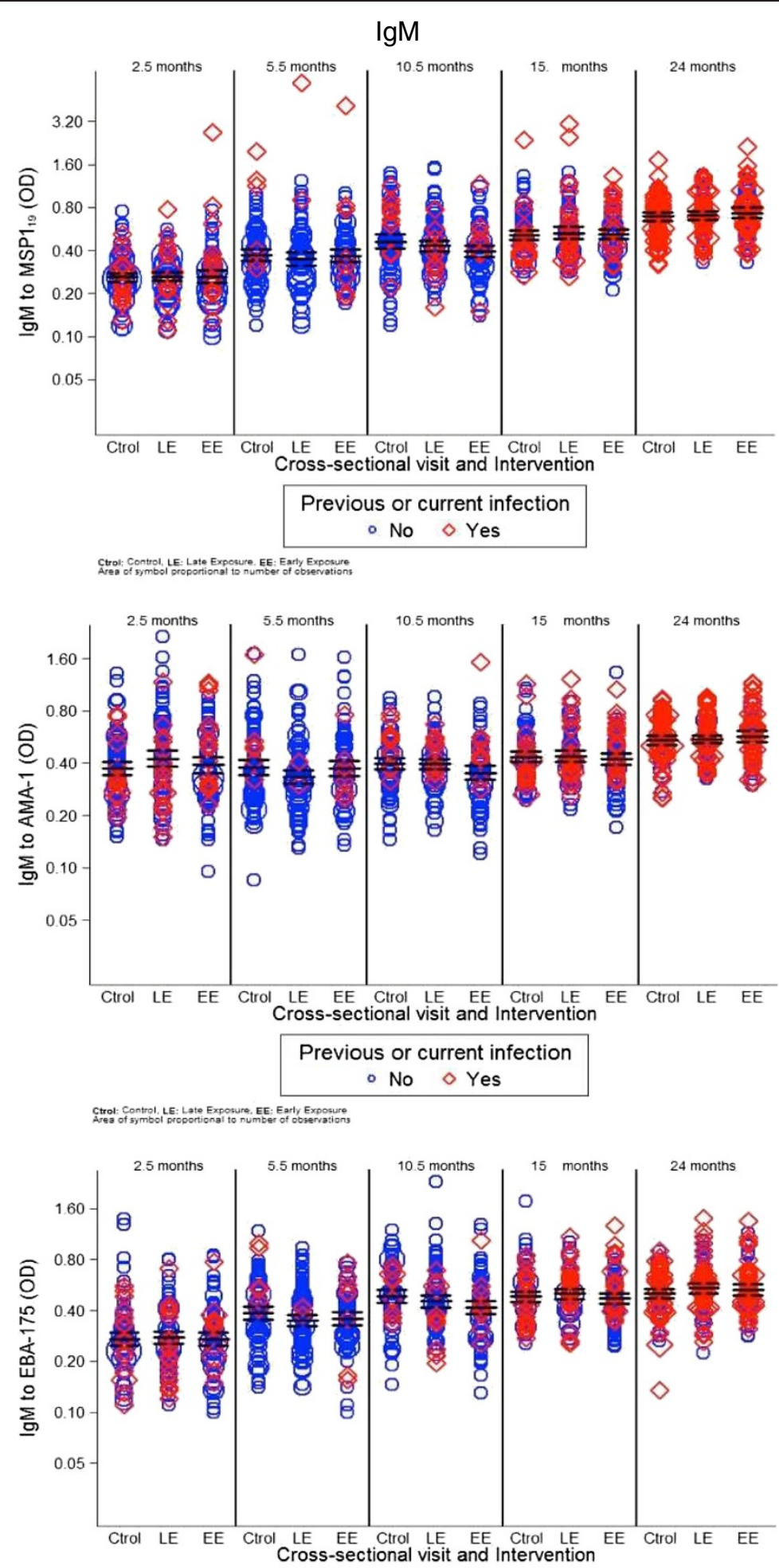

Previous or current infection $\circ$ No $\diamond$ Yes

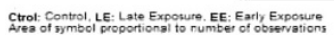

Figure 1 Weighted scatter plots of IgM levels by cross-sectional visit and treatment group. The area of the symbol is proportional to the number of observations. Red symbols correspond to lgM levels in those children with previous or current Plasmodium falciparum infection. Horizontal continuous and dashed lines indicate geometric means at 95\% confidence interval. 

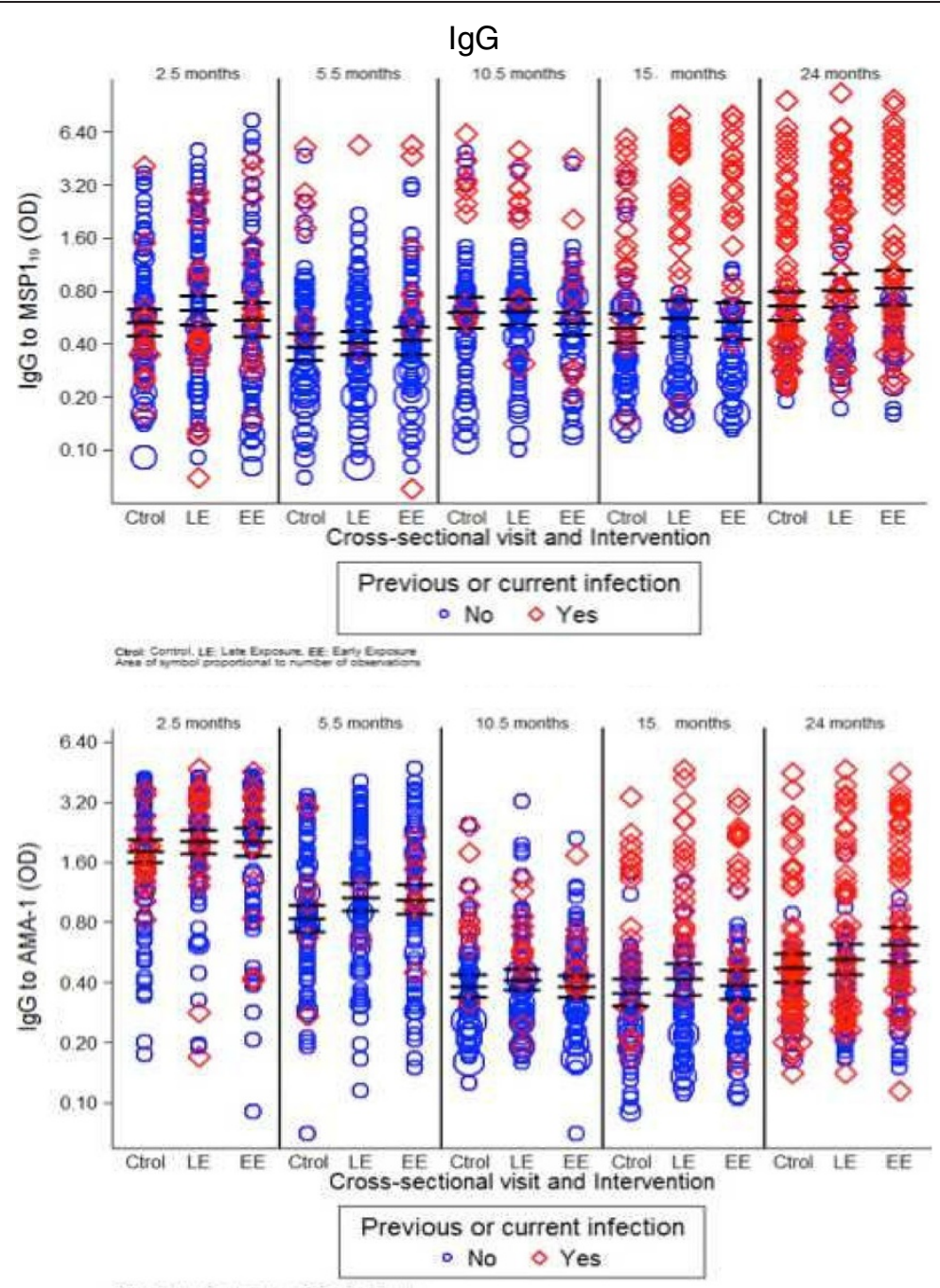

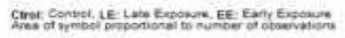

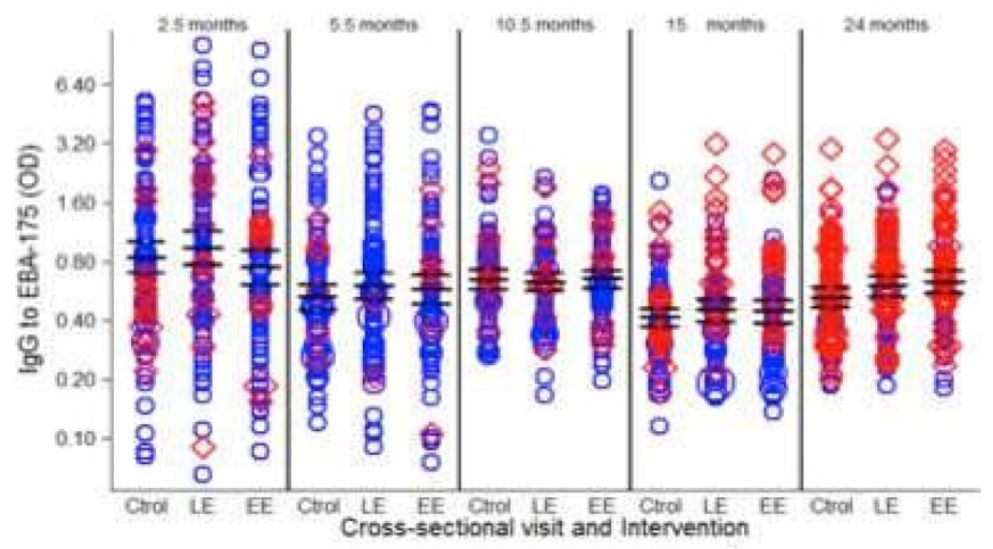

Previous or current infection - No o Yes

is:

Figure 2 Weighted scatter plots of IgG levels by cross-sectional visit and treatment group. Red symbols correspond to lgG levels in those children with previous or current Plasmodium falciparum infection. 


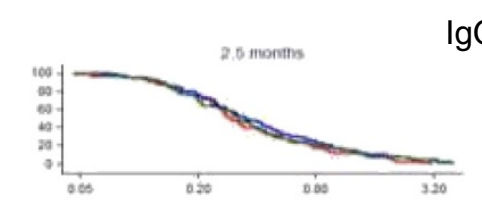

$\lg G$
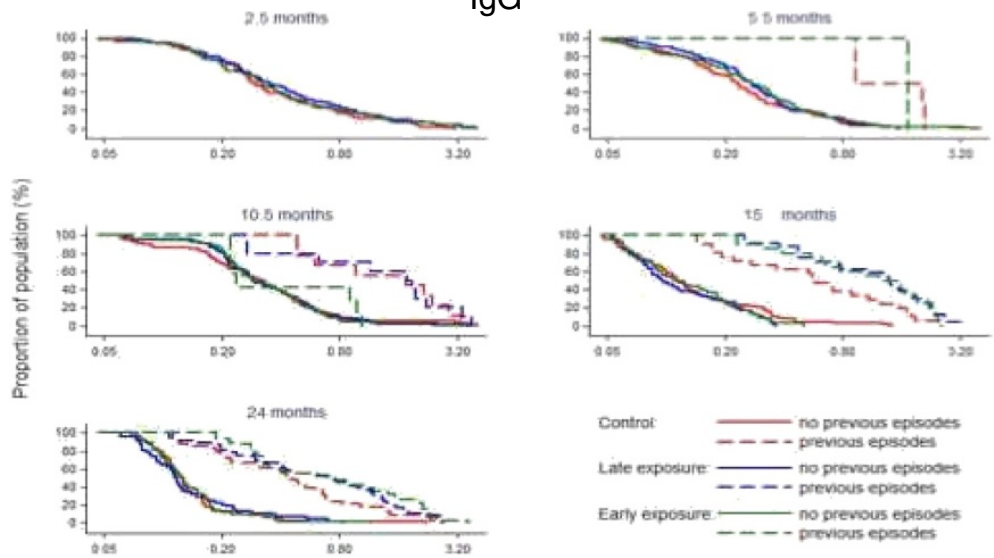

$\operatorname{lgG}$ to $M S P 1_{1}(O D)$
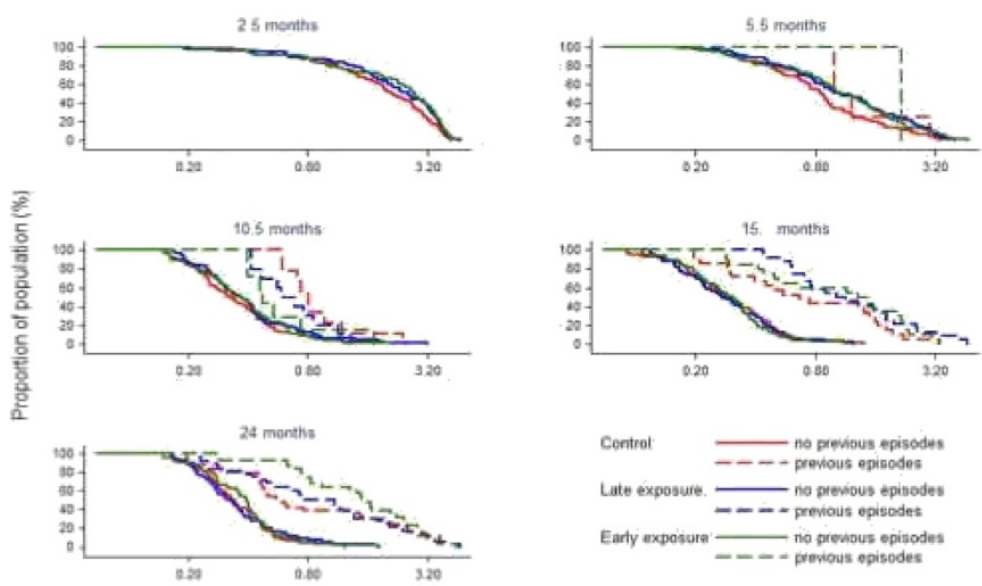

$\lg$ G to AMA-1 (OD)
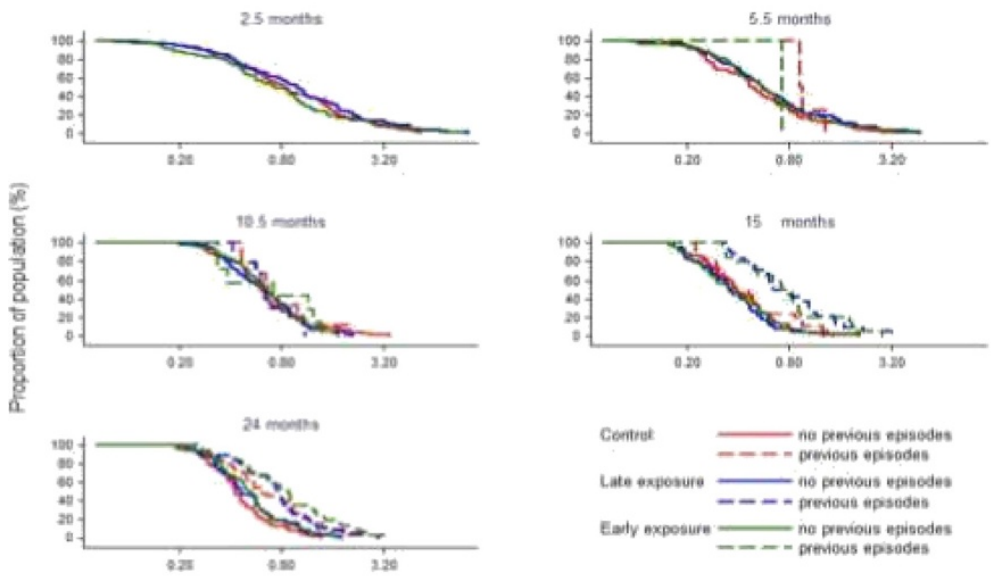

$\lg G$ to EBA-175 (OD)

Figure 3 Reverse empirical distribution function of IgG levels by cross-sectional visit and treatment group in children stratified according to having (dashed line) or not (continuous line) previous episodes of clinical malaria. 

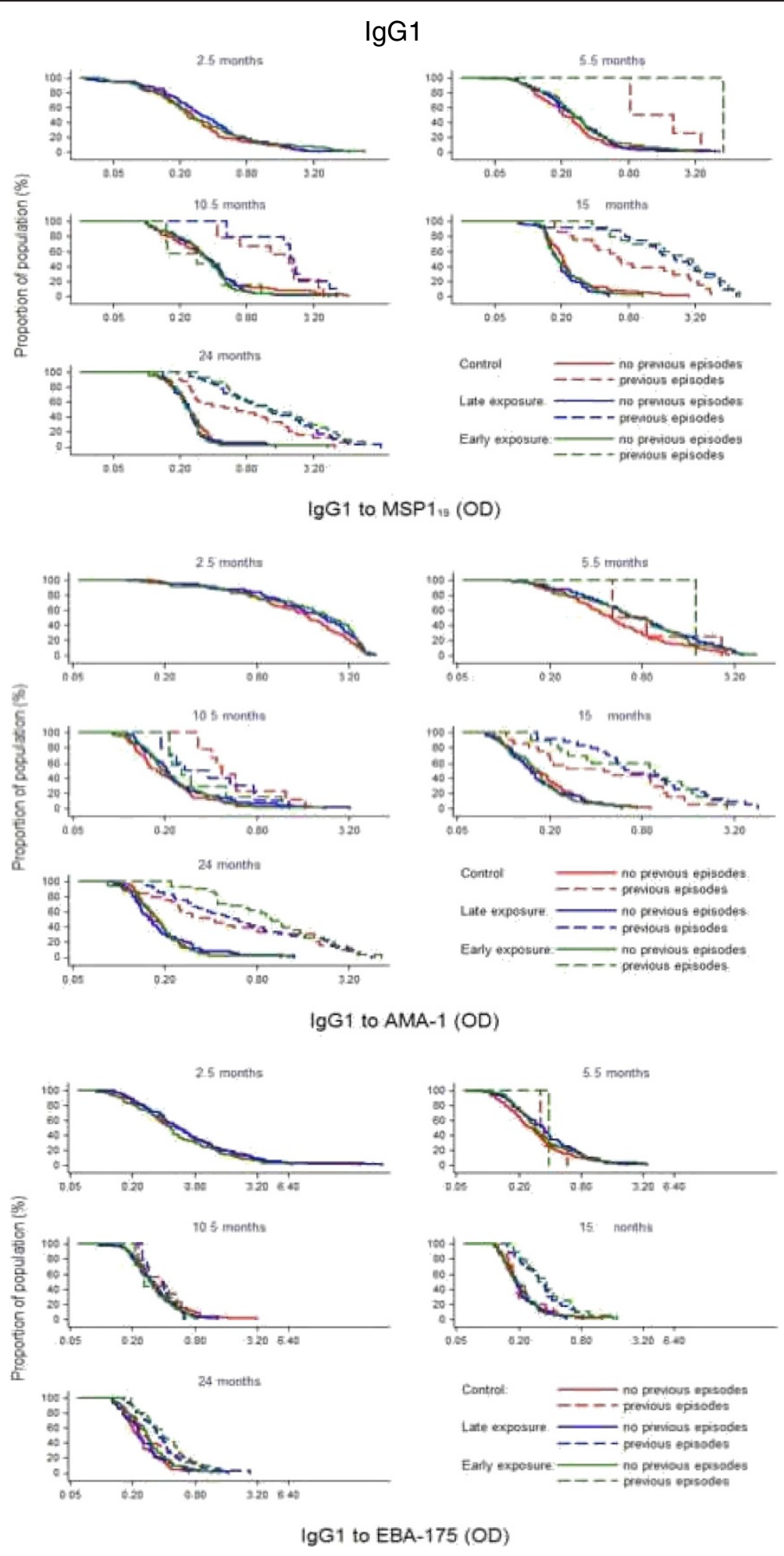

Figure 4 Reverse empirical distribution function of IgG1 levels by cross-sectional visit and treatment group in children stratified according to having (dashed line) or not (continuous line) previous episodes of clinical malaria. 

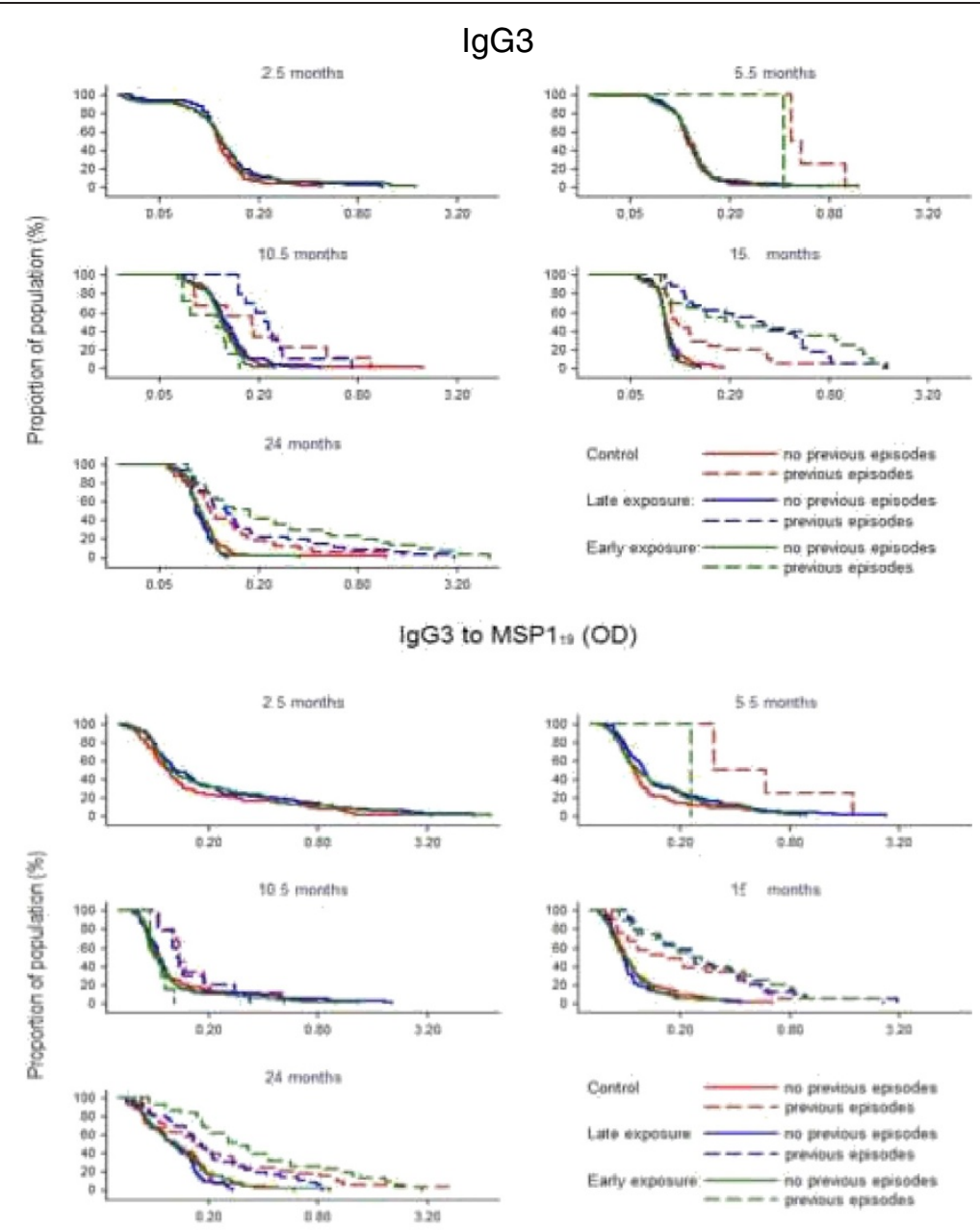

IgG3 to AMA-1 (OD)
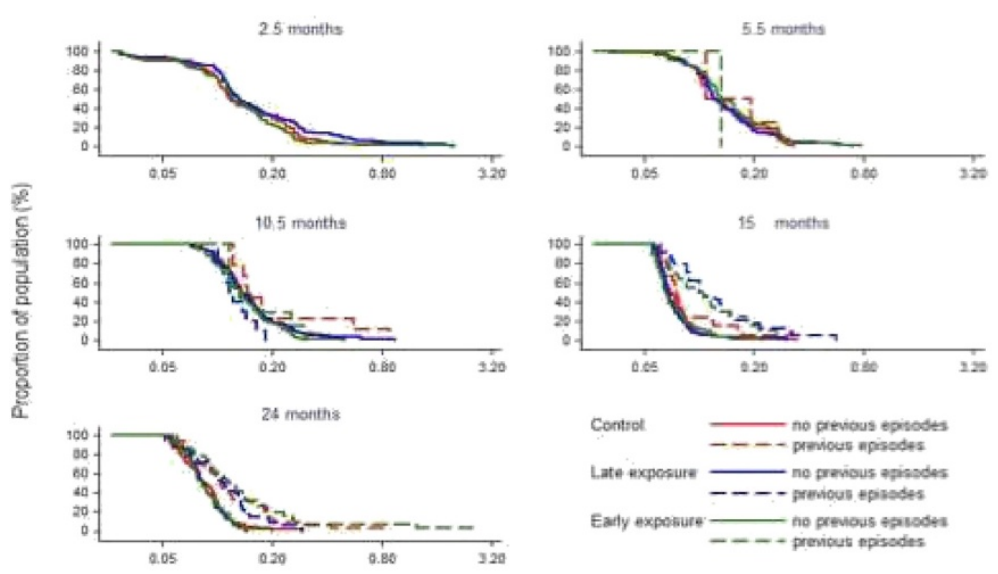

IgG3 to EBA-175 (OD)

Figure 5 Reverse empirical distribution function of lgG3 levels by cross-sectional visit and treatment group in children stratified according to having (dashed line) or not (continuous line) previous episodes of clinical malaria. 
Table 1 Factors independently associated with the magnitude of antibody response by linear regression stepwise analysis

\begin{tabular}{|c|c|c|c|c|c|}
\hline Antibody & Antigen & Variable & $\begin{array}{l}\text { Prop. } \\
\text { diff }^{1}\end{array}$ & $95 \% \mathrm{Cl}$ & $\begin{array}{c}P \\
\text { value }^{2}\end{array}$ \\
\hline \multirow[t]{8}{*}{$\lg G$} & MSP-1 19 & Previous infections & 1.61 & $1.41 ; 1.84$ & $<0.0001$ \\
\hline & & Current infections & 1.39 & $1.74 ; 1.64$ & 0.0001 \\
\hline & & Dry season & 0.88 & $0.80 ; 0.97$ & 0.0084 \\
\hline & AMA-1 & Previous infections & 1.25 & $1.12 ; 1.40$ & 0.0001 \\
\hline & & Current infections & 1.23 & $1.08 ; 1.39$ & 0.0019 \\
\hline & & Dry season & 0.90 & $0.84 ; 0.97$ & 0.005 \\
\hline & EBA-175 & Current infections & 1.13 & $1.01 ; 1.27$ & 0.0389 \\
\hline & & Congenital infections & 1.29 & $1.10 ; 1.52$ & 0.0017 \\
\hline \multirow[t]{11}{*}{$\operatorname{lgG} 1$} & MSP-1 19 & Previous infections & 1.69 & $1.47 ; 1.95$ & 0.0001 \\
\hline & & Current infections & 1.31 & $1.18 ; 1.68$ & 0.0002 \\
\hline & & Low birth weight & 1.31 & $1.06 ; 1.63$ & 0.0143 \\
\hline & AMA-1 & Previous infections & 1.26 & $1.11 ; 1.43$ & 0.0003 \\
\hline & & Current infections & 1.29 & $1.11 ; 1.49$ & 0.0007 \\
\hline & & Dry season & 0.86 & $0.79 ; 0.93$ & 0.0003 \\
\hline & & Placental infection & 1.22 & $1.04 ; 1.43$ & 0.0144 \\
\hline & & Congenital infections & 1.31 & $1.06 ; 1.62$ & 0.0128 \\
\hline & EBA-175 & Previous infections & 1.13 & $1.03 ; 1.59$ & 0.0105 \\
\hline & & Congenital infections & 1.34 & $1.13 ; 1.24$ & 0.0008 \\
\hline & & Dry season & 0.88 & $0.82 ; 0.95$ & 0.0008 \\
\hline \multirow[t]{9}{*}{$\operatorname{lgG} 3$} & MSP-1 19 & Previous infections & 1.14 & $1.06 ; 1.24$ & 0.0009 \\
\hline & & Current infections & 1.54 & $1.38 ; 1.71$ & $<0.0001$ \\
\hline & & Intervention & 1.11 & $1.03 ; 1.20$ & 0.0068 \\
\hline & & Congenital infections & 1.16 & $1.03 ; 1.30$ & 0.0146 \\
\hline & AMA-1 & Previous infections & 1.16 & $1.04 ; 1.29$ & 0.0066 \\
\hline & & Current infections & 1.34 & $1.17 ; 1.52$ & $<0.0001$ \\
\hline & & $\begin{array}{c}\text { Placental } \\
\text { inflammation }\end{array}$ & 1.27 & $1.06 ; 1.53$ & 0.0099 \\
\hline & EBA-175 & Current infections & 1.14 & $1.04 ; 1.24$ & 0.0008 \\
\hline & & Dry season & 1.10 & $1.04 ; 1.16$ & 0.0008 \\
\hline \multirow[t]{4}{*}{$\lg M$} & $\mathrm{MSP} 1_{19}$ & Current infections & 1.16 & $1.09 ; 1.25$ & $<0.0001$ \\
\hline & & Dry season & 1.1 & $1.05 ; 1.15$ & $<0.0001$ \\
\hline & AMA-1 & Dry season & 0.90 & $0.86 ; 0.94$ & $<0.0001$ \\
\hline & EBA-175 & Dry season & 1.07 & $1.03 ; 1.12$ & 0.0009 \\
\hline
\end{tabular}

Models were adjusted for age and neighbourhood, which were also significantly associated with antibody levels $(p<0.0006)$.

${ }^{1}$ The proportional difference for a particular factor is the ratio between the average levels of antibodies in children with the factor vs children without the factor, adjusted for other variables in the model.

${ }^{2} \mathrm{P}$ value using likelihood ratio test.

Antibody levels in relation to the incidence of clinical malaria Two different sets of analyses were conducted at two different time risk intervals: from 2.5 months up to 12 months for the control group only, and from 5.5 months up to 24 months for all groups in the three time periods indicated in Tables 3, 4 and 5 (all children) and Additional file 5 (only control group). In general, no significant associations were found between the antibody levels and subsequent incidence of malaria for both unadjusted and adjusted analysis for the majority of antigens. In some cases, there was an association between higher IgM, IgG and/or IgG1 antibodies to AMA-1 and MSP- $1_{19}$ and increased incidence of malaria (Tables 3, 4 and 5). The only response significantly associated with protection was IgG to EBA-175 whereby double amount of antibodies at 10.5 months correlated with reduced risk of clinical malaria up to 24 months of age follow up (IRR, 95\% CI: 0.67, 0.47-0.94, $\mathrm{p}=0.0178$, adjusted) (Table 4).

\section{Antibody breadth of response in relation to the incidence of clinical malaria}

Breadth of antibody responses in relation to malaria risk was determined only for total IgG and IgM against MSP$1_{19}$, AMA-1, EBA-175 and VSA in all groups (Table 6) and just control group (Additional file 6). Overall, there was an association between higher breadth of response and higher incidence of clinical malaria (IRR $>1$ using $0-1$ as reference group), which reached statistical significance for breadth of IgG responses at 15 months in relation to risk of malaria up to 24 months of age, in both crude and adjusted analyses for either all groups or the control group. The association between higher breadth of response and higher incidence of clinical malaria was also statistically significant at the risk interval between 5.5 months up to 24 months of age when including all children. The IRR values were higher and the $p$ values more significant in crude than in the analyses adjusting for known past/current parasite exposure confounders. Regarding breadth of IgM antibody responses there was no statistically significant association in any risk intervals and group (Table 6, Additional file 6).

\section{Discussion}

This study found no evidence to support that the time of first exposure to blood stage P. falciparum infection, as controlled by SP + AS anti-malarial chemoprophylaxis, has a major influence in the acquisition of antibody responses to the MSP-1 $1_{19}$, AMA-1, EBA-175 and VSA antigens examined. Consistent with the results of the clinical trial [26], the development of naturally acquired immunity within the parameters analysed (total IgM, IgG and subclasses) was not heavily impacted by a substantial disruption of parasite exposure. Significant decreases were only observed in IgM and IgG responses to some antigens in the early exposure group at month 10.5 following chemoprophylaxis, i.e., lower levels of IgM to EBA-175 and lower levels of positive IgG1 and IgG3 responses to MSP- $1_{19}$. Thus, IgM to blood stage antigens at age 10.5 months appeared to be a surrogate 
Table 2 Levels of antibodies at the first episode of clinical malaria (acute) and one month later (convalescence) in relation to the levels of antibodies at the immediately preceding cross-sectional visit (pre-acute) in the three study groups

\begin{tabular}{|c|c|c|c|c|c|c|c|c|c|}
\hline \multirow[t]{2}{*}{ Antibody } & \multirow[t]{2}{*}{ Antigen } & \multirow{2}{*}{$\frac{\text { Pre-acute }}{\mathrm{GM}^{1}}$} & \multicolumn{3}{|c|}{ Acute } & \multicolumn{3}{|c|}{ Convalescent } & \multirow[b]{2}{*}{ P value $^{3}$} \\
\hline & & & $\overline{G M}$ & Prop. diff. $^{2}$ & $95 \% \mathrm{Cl}$ & $\mathrm{GM}$ & Prop. diff. & $95 \% \mathrm{Cl}$ & \\
\hline \multirow[t]{4}{*}{$\lg G$} & MSP-1 $_{19}$ & 0.47 & 0.73 & 1.56 & $1.20 ; 2.02$ & 3.02 & 6.39 & $4.86 ; 8.40$ & $<0.0001$ \\
\hline & AMA-1 & 0.56 & 0.50 & 0.88 & $0.71 ; 1.09$ & 1.01 & 1.80 & $1.44 ; 2.25$ & $<0.0001$ \\
\hline & EBA-175 & 0.53 & 0.41 & 0.77 & $0.65 ; 0.91$ & 0.56 & 1.04 & $0.87 ; 1.24$ & $<0.0013$ \\
\hline & VSA & 17.46 & 8.60 & 0.49 & $0.27 ; 0.91$ & 11.58 & 0.64 & $0.39 ; 1.06$ & $<0.0398$ \\
\hline \multirow[t]{3}{*}{$\lg M$} & $\mathrm{MSP} 1_{19}$ & 0.45 & 0.68 & 1.50 & $1.29 ; 1.73$ & 0.67 & 1.47 & $1.26 ; 1.72$ & $<0.0001$ \\
\hline & AMA-1 & 0.39 & 0.44 & 1.11 & $0.99 ; 1.26$ & 0.48 & 1.23 & $1.08 ; 1.39$ & $<0.0083$ \\
\hline & EBA-175 & 0.42 & 0.49 & 1.14 & $1.03 ; 1.26$ & 0.51 & 1.18 & $1.06 ; 1.31$ & $<0.0046$ \\
\hline \multirow[t]{3}{*}{$\lg G 1$} & MSP-1 $_{19}$ & 0.30 & 0.47 & 1.54 & $1.16 ; 2.04$ & 2.32 & 7.48 & $5.54 ; 10.1$ & $<0.0001$ \\
\hline & AMA-1 & 0.37 & 0.31 & 0.82 & $0.65 ; 1.04$ & 0.64 & 1.73 & $1.35 ; 2.22$ & $<0.0001$ \\
\hline & EBA-175 & 0.31 & 0.21 & 0.69 & $0.59 ; 0.81$ & 0.27 & 0.87 & $0.74 ; 1.03$ & $<0.0001$ \\
\hline \multirow[t]{3}{*}{$\lg G 3$} & $\mathrm{MSP}_{19}$ & 0.11 & 0.15 & 1.30 & $0.99 ; 1.70$ & 0.49 & 4.36 & $3.28 ; 5.78$ & $<0.0001$ \\
\hline & AMA-1 & 0.14 & 0.13 & 0.93 & $0.77 ; 1.12$ & 0.29 & 2.04 & $1.66 ; 2.50$ & $<0.0001$ \\
\hline & EBA-175 & 0.11 & 0.07 & 0.61 & $0.52 ; 0.72$ & 0.09 & 0.80 & $0.67 ; 0.95$ & $<0.0001$ \\
\hline
\end{tabular}

${ }^{1}$ Geometric means.

${ }^{2}$ The proportional difference is the ratio between the average levels of antibodies from acute (or convalescent) samples vs the levels from pre-acute samples, taking into account repeated measures for children.

${ }^{3} \mathrm{P}$ value from Mixed-effects linear regression models using Likelihood Ratio Test.

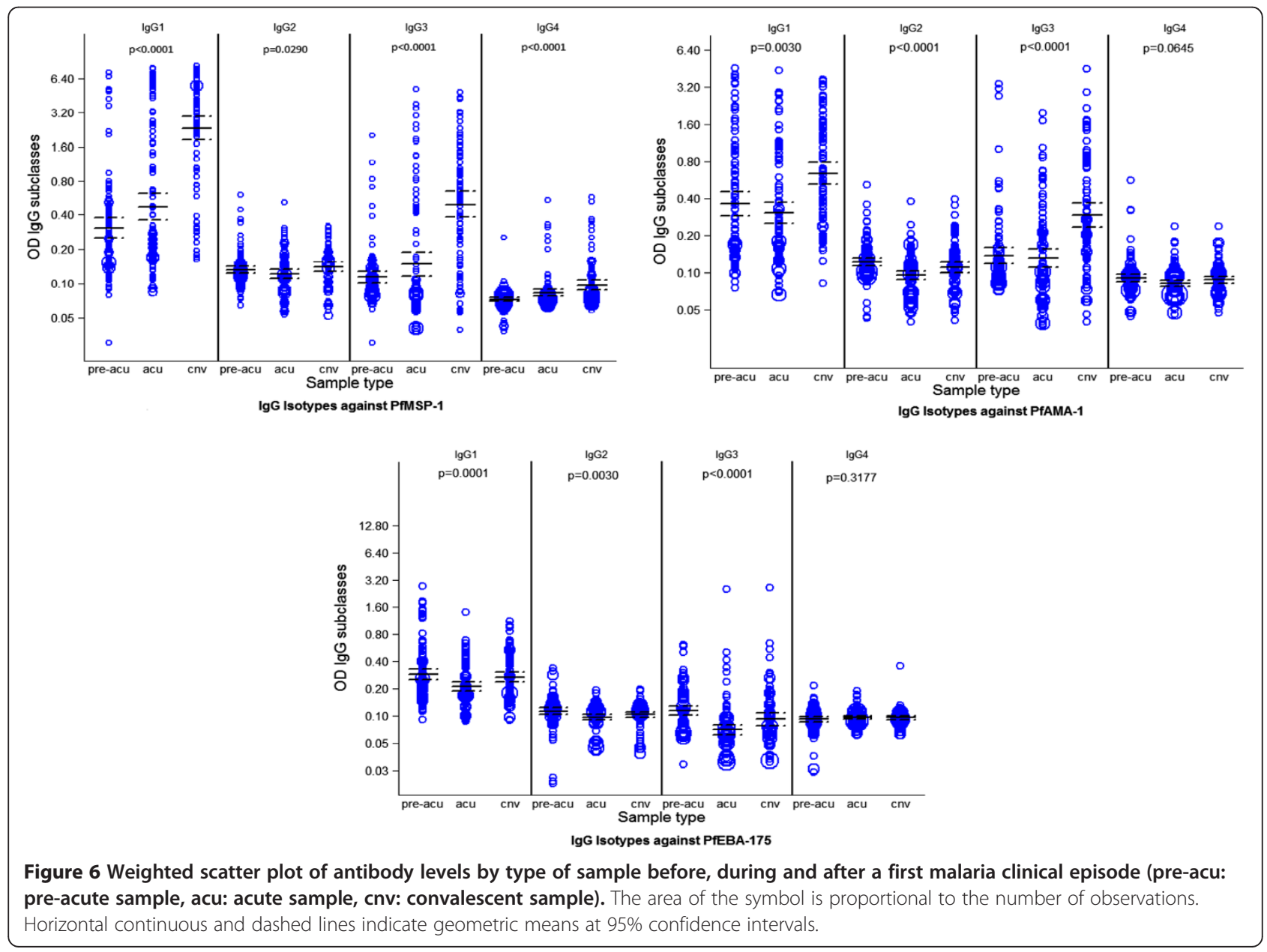


Table 3 Association between levels of antibodies (two-fold increment) at 5.5 months of age and the incidence of malaria up to 24 months of age

\begin{tabular}{|c|c|c|c|c|c|c|c|}
\hline \multirow{3}{*}{ Antigens } & \multirow{3}{*}{ Antibodies } & \multicolumn{6}{|c|}{ 5.5-24 months } \\
\hline & & \multicolumn{3}{|c|}{ Crude } & \multicolumn{3}{|c|}{ Adjusted } \\
\hline & & $\overline{\text { IRR }^{1}}$ & $95 \% \mathrm{Cl}$ & P value $^{2}$ & IRR & $95 \% \mathrm{Cl}$ & $P$ value \\
\hline \multirow{6}{*}{$\mathrm{MSP} 1_{19}$} & $\lg G$ & 1.09 & $0.90 ; 1.33$ & 0.3783 & 0.96 & $0.78 ; 1.17$ & 0.6853 \\
\hline & $\lg G 1$ & 1.10 & $0.90 ; 1.33$ & 0.3525 & 0.96 & $0.79 ; 1.17$ & 0.6872 \\
\hline & $\lg G 2$ & 1.33 & $0.72 ; 2.45$ & 0.3594 & 1.05 & $0.61 ; 1.83$ & 0.8519 \\
\hline & $\lg G 3$ & 1.20 & $0.87 ; 1.65$ & 0.2508 & 0.93 & $0.67 ; 1.29$ & 0.6599 \\
\hline & $\lg G 4$ & 0.66 & $0.27 ; 1.60$ & 0.3526 & 0.48 & $0.21 ; 1.14$ & 0.0970 \\
\hline & $\lg M$ & 1.35 & $0.96 ; 1.89$ & 0.0768 & 1.27 & $0.88 ; 1.85$ & 0.2013 \\
\hline \multirow[t]{6}{*}{ AMA-1 } & $\lg G$ & 2.01 & $1.58 ; 2.56$ & $<0.0001$ & 1.64 & $1.29 ; 2.09$ & $<0.0001$ \\
\hline & $\lg G 1$ & 1.81 & $1.48 ; 2.22$ & $<0.0001$ & 1.54 & $1.25 ; 1.89$ & $<0.0001$ \\
\hline & $\lg G 2$ & 1.12 & $0.75 ; 1.66$ & 0.5840 & 0.91 & $0.61 ; 1.36$ & 0.6415 \\
\hline & $\lg G 3$ & 1.38 & $1.05 ; 1.82$ & 0.0169 & 1.15 & $0.89 ; 1.47$ & 0.2803 \\
\hline & $\lg G 4$ & 1.27 & $0.69 ; 2.33$ & 0.4396 & 0.94 & $0.50 ; 1.78$ & 0.8496 \\
\hline & $\lg M$ & 1.33 & $0.89 ; 2.00$ & 0.1590 & 1.16 & $0.79 ; 1.70$ & 0.4468 \\
\hline \multirow[t]{6}{*}{ EBA-175 } & $\lg G$ & 1.29 & $1.04 ; 1.60$ & 0.0177 & 1.11 & $0.90 ; 1.37$ & 0.3323 \\
\hline & $\lg G 1$ & 1.36 & $1.08 ; 1.72$ & 0.0077 & 1.21 & $0.97 ; 1.50$ & 0.0916 \\
\hline & $\lg G 2$ & 1.21 & $0.69 ; 2.12$ & 0.4981 & 1.21 & $0.72 ; 2.04$ & 0.4614 \\
\hline & $\lg G 3$ & 1.34 & $0.97 ; 1.83$ & 0.0701 & 1.20 & $0.89 ; 1.63$ & 0.2324 \\
\hline & $\lg G 4$ & 0.91 & $0.45 ; 1.82$ & 0.7837 & 1.09 & $0.57 ; 2.07$ & 0.7936 \\
\hline & $\lg M$ & 1.57 & $1.04 ; 2.38$ & 0.0338 & 1.41 & $0.94 ; 2.12$ & 0.0996 \\
\hline VSA & $\lg G$ & 1.42 & $1.10 ; 1.84$ & 0.0069 & 1.55 & $1.19 ; 2.01$ & 0.0008 \\
\hline
\end{tabular}

Analysis done by negative binomial regression models adjusted by treatment, season, neighbourhood, current infection, previous infection, maternal infection, congenital infection, placental inflammation, insecticide-treated bed net use, and indoor residual spraying.

${ }^{1}$ Incidence rate ratio.

${ }^{2}$ Negative binomial regression model using likelihood ratio test.

of recent $P$. falciparum exposure. Maternal IgG levels were high at 2.5 months in all groups before waning over the first year. The conclusion of this first analysis was that, overall, a 3-5 month-long drug intervention had no major impact on $P$. falciparum-specific IgG levels in these young infants in face of high levels of maternal IgG antibodies still circulating in their plasma. Because of the confounding effect of these passively transferred antibodies, the impact of the study interventions on IgG levels during the first year of life and the impact of IgG responses during the first year of life on subsequent risk of malaria were difficult to ascertain.

Of note, children who received chemoprophylaxis during the first year of life and suffered previous malaria infections were characterized by an increase in antibody levels in the second year, as observed in the stratified cumulative distribution plots (Figures 3, 4 and 5). This pattern appeared to be parallel to the Kaplan Meier survival curves for cumulative proportion of children with at least one episode of malaria during the second year of follow-up, which showed a trend for a higher incidence of malaria in year 2 in the late and early exposure groups when compared to the control group [26]. Thus, these increased IgG antibody levels in children with documented parasite exposure reflected the higher incidence of malaria in the second year in those who received chemoprophylaxis in the first year. Therefore, antibodies to these blood stage antigens appeared to be mostly markers of exposure, and this is consistent with the strong association between previous or concurrent infection and IgG levels and breadth demonstrated here and in previous studies by our group [34,35]. Indeed, data show that high levels of antibody responses to antigens such as AMA-1 are commonly associated with greater future risk of malaria, presumably because children with increased antibodies levels or breadth are also those who have suffered more previous episodes of malaria and/or prenatal parasite exposure, a known and strong risk factor for subsequent malaria episodes $[32,34,36]$. This is in contrast to other studies showing an association between AMA-1 $[3,16,37,38]$ or MSP- $1_{19}[4,16,39]$ responses and reduced risk of malaria. Even though, for example, antiAMA-1 IgG antibodies are described as some times protective [3] while other non-protective [40], many studies 
Table 4 Association between levels of antibodies (two-fold increment) at $\mathbf{1 0 . 5}$ months of age and the incidence of malaria up to 24 months of age

\begin{tabular}{|c|c|c|c|c|c|c|c|}
\hline \multirow{3}{*}{ Antigens } & \multirow{3}{*}{ Antibodies } & \multicolumn{6}{|c|}{ 10.5-24 months } \\
\hline & & \multicolumn{3}{|c|}{ Crude } & \multicolumn{3}{|c|}{ Adjusted } \\
\hline & & $\overline{\mathrm{IRR}^{1}}$ & $95 \% \mathrm{Cl}$ & P value $^{2}$ & IRR & $95 \% \mathrm{Cl}$ & $\overline{P \text { value }}$ \\
\hline \multirow[t]{6}{*}{$\mathrm{MSP} 1_{19}$} & $\lg G$ & 1.26 & $1.03 ; 1.55$ & 0.0269 & 1.15 & $0.94 ; 1.40$ & 0.1710 \\
\hline & $\lg G 1$ & 1.23 & $1.01 ; 1.49$ & 0.0385 & 1.13 & $0.94 ; 1.36$ & 0.2081 \\
\hline & $\lg G 2$ & 0.82 & $0.45 ; 1.49$ & 0.5226 & 0.76 & $0.45 ; 1.27$ & 0.2968 \\
\hline & $\lg G 3$ & 1.19 & $0.77 ; 1.82$ & 0.4235 & 0.94 & $0.63 ; 1.39$ & 0.7423 \\
\hline & $\operatorname{lgG} 4$ & 1.35 & $0.75 ; 2.42$ & 0.3096 & 1.27 & $0.69 ; 2.33$ & 0.4361 \\
\hline & $\lg M$ & 0.98 & $0.65 ; 1.49$ & 0.9419 & 1.01 & $0.70 ; 1.45$ & 0.9654 \\
\hline \multirow[t]{6}{*}{ AMA-1 } & $\lg G$ & 1.86 & $1.37 ; 2.53$ & $<0.0001$ & 1.31 & $1.00 ; 1.72$ & 0.0533 \\
\hline & $\lg G 1$ & 1.68 & $1.26 ; 2.25$ & 0.0002 & 1.21 & $0.94 ; 1.57$ & 0.1366 \\
\hline & $\lg G 2$ & 1.12 & $0.57 ; 2.23$ & 0.7446 & 0.98 & $0.57 ; 1.67$ & 0.9354 \\
\hline & $\lg G 3$ & 1.06 & $0.71 ; 1.59$ & 0.7446 & 0.98 & $0.71 ; 1.33$ & 0.8743 \\
\hline & $\operatorname{lgG} 4$ & 2.78 & $1.13 ; 6.81$ & 0.0261 & 1.85 & $0.83 ; 4.14$ & 0.1360 \\
\hline & $\lg M$ & 1.65 & $0.94 ; 2.87$ & 0.0811 & 2.08 & $1.26 ; 3.45$ & 0.0037 \\
\hline \multirow[t]{6}{*}{ EBA-175 } & $\lg G$ & 0.73 & $0.50 ; 1.09$ & 0.1235 & 0.67 & $0.47 ; 0.94$ & 0.0178 \\
\hline & $\lg G 1$ & 0.75 & $0.50 ; 1.13$ & 0.1735 & 0.75 & $0.54 ; 1.04$ & 0.0874 \\
\hline & $\lg G 2$ & 0.74 & $0.50 ; 1.09$ & 0.1124 & 0.69 & $0.50 ; 0.90$ & 0.0239 \\
\hline & $\lg G 3$ & 0.90 & $0.58 ; 1.40$ & 0.6580 & 0.80 & $0.55 ; 1.17$ & 0.2469 \\
\hline & $\operatorname{lgG} 4$ & 0.89 & $0.56 ; 1.41$ & 0.6152 & 0.75 & $0.49 ; 1.14$ & 0.1741 \\
\hline & $\lg M$ & 1.12 & $0.72 ; 1.74$ & 0.6113 & 1.48 & $1.02 ; 2.14$ & 0.0358 \\
\hline VSA & $\lg G$ & 1.02 & $0.76 ; 1.36$ & 0.8827 & 0.92 & $0.68 ; 1.24$ & 0.5864 \\
\hline
\end{tabular}

Analysis done by negative binomial regression models adjusted by treatment, season, neighbourhood, current infection, previous infection, maternal infection, congenital infection, placental inflammation, insecticide-treated bed net use, and indoor residual spraying.

${ }^{1}$ Incidence rate ratio.

${ }^{2}$ Negative binomial regression model using likelihood ratio test.

fail to establish any significant association [41]. Dissimilarities between reports may be partially related to differences in age between participants, under two years old in this study $v s$ older children or adults in other studies. However, a prominent factor that influence immune correlates analysis is heterogeneity in parasite exposure at the individual level. The challenges of establishing protective associations between antibody responses and malaria susceptibility if prior and present infections are not registered and taken into account in the analysis are increasingly being recognized. The only instance in which there was a protective association between higher levels of antibodies and reduced incidence of malaria was for the EBA-175 antigen, and this was mostly shown after analyses were adjusted for previous malaria episodes. Since this result has consistently been reproduced in two other studies in the same area with two different groups of children [35,42], it is concluded that among the antigen targets evaluated, EBA-175 is the most promising blood stage candidate for vaccine development.

Factors affecting the magnitude of anti-malarial antibodies were analysed in detail. Previous studies report that increasing age (particularly for AMA-1), heterogeneity of exposure, proximity to swamps, and higher previous exposure are significant predictors of higher antibody responses $[4,32,35]$. In this study, age was also the most prominent factor significantly influencing the levels of all antibodies. In addition, factors associated to concurrent or past parasite exposure, including during gestation and birth, generally affected antibody levels in these infants. Season and particular neighbourhoods had increased antibody prevalences, however it was not possible to define the geographic characteristics (e. g., proximity to swamps) explaining the differences. This study was limited in that it could not fully evaluate individual heterogeneity of exposure and differential antibody levels in relation to geographical parameters influencing malaria transmission intensity.

In these very young children, anti-VSA IgG responses were not prominent. Levels were very low and dependent on neighbourhood and age, with an overall pattern showing higher maternally derived IgG waning over time. This was in contrast to studies in a different endemic area of Tanzania where the level of antibodies increased with age 
Table 5 Association between levels of antibodies (two-fold increment) at 15 months of age and the incidence of malaria up to 24 months of age

\begin{tabular}{|c|c|c|c|c|c|c|c|}
\hline \multirow{3}{*}{ Antigens } & \multirow{3}{*}{ Antibodies } & \multicolumn{6}{|c|}{ 15-24 months } \\
\hline & & \multicolumn{3}{|c|}{ Crude } & \multicolumn{3}{|c|}{ Adjusted } \\
\hline & & $\overline{\mathrm{IRR}^{1}}$ & $95 \% \mathrm{Cl}$ & P value $^{2}$ & $\overline{\text { IRR }}$ & $95 \% \mathrm{Cl}$ & $P$ value \\
\hline \multirow[t]{6}{*}{$\mathrm{MSP} 1_{19}$} & $\lg G$ & 1.56 & $1.33 ; 1.82$ & $<0.0001$ & 1.29 & $1.06 ; 1.57$ & 0.0121 \\
\hline & $\lg G 1$ & 1.62 & $1.39 ; 1.90$ & $<0.0001$ & 1.37 & $1.13 ; 1.66$ & 0.0011 \\
\hline & $\lg G 2$ & 2.14 & $1.07 ; 4.27$ & 0.0260 & 1.37 & $0.71 ; 2.28$ & 0.4141 \\
\hline & $\lg G 3$ & 1.84 & $1.36 ; 2.48$ & $<0.0001$ & 1.32 & $0.98 ; 1.77$ & 0.0591 \\
\hline & $\operatorname{lgG} 4$ & 2.22 & $0.79 ; 6.21$ & 0.1033 & 1.35 & $0.60 ; 3.05$ & 0.4694 \\
\hline & $\lg M$ & 0.83 & $0.53 ; 1.31$ & 0.4290 & 0.84 & $0.55 ; 1.27$ & 0.4027 \\
\hline \multirow[t]{6}{*}{ AMA-1 } & $\lg G$ & 1.87 & $1.52 ; 2.30$ & $<0.0001$ & 1.43 & $1.14 ; 1.79$ & 0.0023 \\
\hline & $\lg G 1$ & 1.96 & $1.61 ; 2.38$ & $<0.0001$ & 1.55 & $1.27 ; 1.90$ & $<0.0001$ \\
\hline & $\lg G 2$ & 2.32 & $1.21 ; 4.44$ & 0.0086 & 1.89 & $1.12 ; 3.20$ & 0.0161 \\
\hline & $\lg G 3$ & 1.99 & $1.48,2.67$ & $<0.0001$ & 1.41 & $1.08 ; 1.83$ & 0.0113 \\
\hline & $\lg G 4$ & 2.55 & $1.24 ; 5.23$ & 0.0088 & 1.71 & $0.95 ; 3.05$ & 0.0723 \\
\hline & $\lg M$ & 0.78 & $0.45 ; 1.37$ & 0.3973 & 0.64 & $0.39 ; 1.04$ & 0.0715 \\
\hline \multirow[t]{6}{*}{ EBA-175 } & $\lg G$ & 1.48 & $1.08 ; 2.04$ & 0.0141 & 1.14 & $0.83 ; 1.57$ & 0.4052 \\
\hline & $\lg G 1$ & 1.78 & $1.19 ; 2.68$ & 0.0040 & 1.31 & $0.91 ; 1.89$ & 0.1442 \\
\hline & $\lg G 2$ & 0.88 & $0.42 ; 1.82$ & 0.7257 & 0.55 & $0.27 ; 1.10$ & 0.0898 \\
\hline & $\lg G 3$ & 1.80 & $1.03 ; 3.15$ & 0.0283 & 0.96 & $0.63 ; 1.48$ & 0.8697 \\
\hline & $\operatorname{lgG} 4$ & 1.40 & $0.62 ; 3.17$ & 0.4025 & 0.98 & $0.51 ; 1.89$ & 0.9600 \\
\hline & $\lg M$ & 0.65 & $0.36 ; 1.17$ & 0.1510 & 0.72 & $0.42 ; 1.20$ & 0.2133 \\
\hline VSA & $\lg G$ & 1.68 & $1.18 ; 2.38$ & 0.0034 & 1.29 & $0.94 ; 1.76$ & 0.1105 \\
\hline
\end{tabular}

Analysis done by negative binomial regression models adjusted by treatment, season, neighbourhood, current infection, previous infection, maternal infection, congenital infection, placental inflammation, insecticide-treated bed net use, and indoor residual spraying.

${ }^{1}$ Incidence rate ratio.

${ }^{2}$ Negative binomial regression model using likelihood ratio test.

from five to 24 months [22]. The results of this study do not support acquisition of VSA IgG by the age of two years in the Manhiça population at the time of the clinical trial. There was a lack of association between these antibodies and current malaria infection, in contrast to what was observed in another study conducted in the same area at a different time [29], and in Tanzania [22]. This suggests that in these children, anti-VSA IgG were not involved in early acquisition of immunity, presumably due to the high variability of PfEMP-1 antigens and the lower level of exposure during this limited time.

Breadth of antibody response has been suggested to be an important predictor of protection from clinical malaria in Kenyan children [9], with an inverse association between increasing breadth of IgG antibody specificities and risk of malaria, and none of the children who simultaneously had high antibody levels to five or more antigens experiencing a clinical episode. Studies assessing interaction between breadth and risk of malaria are limited. Here, using only four antigens, a direct association between breadth of IgG response and subsequent incidence of malaria was either not detected or observed at two different follow up periods (5.5-24 and 15-24 months of age), in contrast to the Kenyan study but in the same line as the relationship between magnitude of antibody responses and malaria risk. In Manhiça, the association between IgG antigenic breadth and incidence of malaria was stronger in the unadjusted analysis and weaker when controlling for variables related to parasite exposure, suggesting that it was highly affected by prior infection but that we not were able to remove all the confounders. Thus, in immune correlates analyses in mother-child cohorts it remains a challenge to account for absolute parasite exposures when using a primarily passive surveillance design, particularly to detect those infections that may be asymptomatic and not accounted for in the adjusted analyses.

\section{Conclusion}

The age of first $P$. falciparum exposure seemed not to be critical for acquisition of protective immunity as evaluated by acquisition of antibody responses to blood stage antigens that are candidate targets for malaria vaccine development. Overall, the breadth and magnitude of antibody responses were strongly influenced by 
Table 6 Association between breadth of antibody response and the incidence of malaria in all chemoprophylactic groups up to 24 months of age

\begin{tabular}{|c|c|c|c|c|c|c|c|c|c|c|c|}
\hline \multirow{3}{*}{$\mathrm{Abs}^{1}$} & \multirow{3}{*}{ Time } & \multicolumn{10}{|c|}{ All groups } \\
\hline & & \multicolumn{5}{|c|}{ Crude } & \multicolumn{5}{|c|}{ Adjusted } \\
\hline & & $\overline{\mathrm{Bth}^{2}}$ & $\mathrm{~N}^{3}$ & $\mathrm{IRR}^{4}$ & $95 \% \mathrm{Cl}$ & $P$ value ${ }^{5}$ & $\overline{\text { Bth }}$ & $\mathrm{N}$ & IRR & $95 \% \mathrm{Cl}$ & $\overline{P \text { value }}$ \\
\hline \multirow[t]{10}{*}{$\lg G$} & 5.5-24 months & $0-1$ & 152 & 1 & - & 0.0005 & $0-1$ & 152 & 1 & - & 0.0143 \\
\hline & & 2 & 47 & 3.50 & $1.79 ; 6.84$ & & 2 & 47 & 2.64 & $1.38 ; 5.06$ & \\
\hline & & 3 & 9 & 3.17 & $0.82 ; 12.28$ & & 3 & 9 & 1.86 & $0.48 ; 7.24$ & \\
\hline & 10.5-24 months & $0-1$ & 189 & 1 & - & 0.3412 & $0-1$ & 189 & 1 & - & 0.4438 \\
\hline & & 2 & 3 & 4.42 & $0.39 ; 49.95$ & & 2 & 3 & 0.89 & $0.09 ; 8.41$ & \\
\hline & & 3 & 1 & 0.85 & $0.01 ; 75.19$ & & 3 & 1 & 11.72 & $0.29 ; 504.65$ & \\
\hline & 15-24 months & $0-1$ & 185 & 1 & - & $<0.0001$ & $0-1$ & 185 & 1 & - & 0.0297 \\
\hline & & 2 & 19 & 8.56 & $3.68 ; 19.94$ & & 2 & 19 & 3.29 & $1.49 ; 7.29$ & \\
\hline & & 3 & 5 & 5.42 & $1.11 ; 26.52$ & & 3 & 5 & 2.30 & $0.55 ; 9.54$ & \\
\hline & & 4 & 1 & 13.68 & $0.48 ; 388.95$ & & 4 & 1 & 6.14 & $0.52 ; 71.92$ & \\
\hline \multirow[t]{9}{*}{$\lg M$} & 5.5-24 months & 0 & 265 & 1 & - & 0.9316 & 0 & 265 & 1 & - & 0.1472 \\
\hline & & 1 & 23 & 1.04 & $1.04 ; 2.63$ & & 1 & 23 & 0.50 & $0.20 ; 1.26$ & \\
\hline & 10.5-24 months & 0 & 246 & 1 & - & 0.2402 & 0 & 246 & 1 & - & 0.6655 \\
\hline & & 1 & 16 & 0.40 & $0.12 ; 1.35$ & & 1 & 16 & 1.22 & $0.41 ; 3.62$ & \\
\hline & & 2 & 4 & 2.36 & $0.30 ; 18.24$ & & 2 & 4 & 1.91 & $0.40 ; 9.11$ & \\
\hline & 15-24 months & 0 & 246 & 1 & - & 0.8912 & 0 & 246 & 1 & - & 0.7638 \\
\hline & & 1 & 14 & 1.00 & $0.28 ; 3.58$ & & 1 & 14 & 0.58 & $0.16 ; 2.09$ & \\
\hline & & 2 & 5 & 2.08 & $0.29 ; 15.04$ & & 2 & 5 & 1.56 & $0.32 ; 7.57$ & \\
\hline & & 3 & 1 & 0.97 & $0.01 ; 91.36$ & & 3 & 1 & 0.79 & $0.03 ; 19.06$ & \\
\hline
\end{tabular}

Analysis done by negative binomial regression. All chemoprophylactic groups were assessed in three risk intervals: from 5.5 months to 24 months, from 10.5 to 24 months and from 15.5 to 24 months. The strength of the association between breadth of response and malaria risk was assessed first unadjusted and after adjusting by treatment, age, season, neighbourhood, current infection, previous infection, maternal infection, congenital infection, placental inflammation, insecticide-treated bed net use, and indoor residual spraying.

${ }^{1}$ Antibody types.

${ }^{2}$ Breadth of antibodies.

${ }^{3}$ Number of children.

${ }^{4}$ Incidence rate ratio.

${ }^{5}$ Negative binomial regression model using likelihood ratio test.

previous exposure and age. Only levels of IgG to EBA175 were associated with reduced incidence of malaria in the second year of life. It remains to be assessed whether the intervention might have an impact on the quality of antibody responses such as affinity/avidity, fine specificity or functionality, and on cellular immune responses also thought to contribute to naturally acquired immunity.

\section{Additional files}

Additional file 1: Comparison of the anti-variant surface antigens (VSA) Immunoglobulin (Ig) G antibody responses. Differences in anti-VSA IgG antibodies levels among chemoprophylaxis groups, at the five sampling study visits; assessed by ANOVA.

Additional file 2: Variables associated to antibody levels assessed by multilevel regression model. Analyse of variables associated with antibody levels assessed by mixed-effects linear regression models including the following variables: intervention group, age, season, neighbourhood, previous infection, current infection, low birth weight, placental infection, placental inflammation and congenital infection.

Additional file 3: Association between different neighborhoods and antibody levels. Proportional differences and P-values of the association between neighbourhood and the magnitude of antibody response by linear regression analysis.

Additional file 4: District map of the Manhiça study area. Group of study regions and distribution of study participants per neighbourhood (bairros).

Additional file 5: Magnitude of antibody response related to incidence of clinical malaria only in control group. Association between levels of antibodies (2-fold increment) at 2.5 months of age and the incidence of malaria up to 12 and 24 months of age, only for the placebo control group. Analysis done by negative binomial regression models adjusted by season, neighborhood, current infection, previous infection, maternal infection, congenital infection, placental inflammation, insecticide treated bednet use and indoor residual spraying.

Additional file 6: Breadth of antibody response related to incidence of clinical malaria only in control group. Analysis done by negative binomial regression. Participants of control group were assessed in five risk intervals: from 2.5 months to 12 months, from 2.5 months to 24 months, from 5.5 months to 24 months, from 10.5 to 24 months and 
from 15.5 to 24 months. The strength of the association between breadth of response and malaria risk was assessed first unadjusted and after adjusting by treatment, age, season, neighbourhood, current infection, previous infection, maternal infection, congenital infection, placental inflammation, insecticide treated bednet use and indoor residual spraying.

\section{Competing interests}

The authors declare that they have no competing interests.

\section{Authors' contributions}

$P A, J J A$ and $C D$ conceived and designed the field trial: CG, QB, AN, MNM, AB, and MHR conducted the field trial and follow-up of participants; CD and AM conceived and designed the experiments; CEC produced recombinant proteins; AN, AJ, MNM, RA, MHR, AB, and PC processed samples and performed laboratory analysis; LQ and JJA analysed the data; AN and CD wrote the paper. All authors contributed to the interpretation of the results and writing of the manuscript. All authors read and approved the final manuscript.

\section{Acknowledgements}

We are thankful to the study participants and their supportive families, the study nurses at the hospitals of Maragra and Manhiça, field workers and supervisors, data clerks and managers, and all CISM staff contributing to this study. We are especially grateful to Laura Puyol, Nelito Ernesto Jose, Lazaro Quimice, Ana Rosa, and Salvador Mesa for their laboratory support, and Lucinda Araujo for the quality control.

\section{Funding statement}

The study was funded by an EU Framework Programme 6 STREP project (Malaria age exposure, Project reference 18902), the Instituto de Salud Carlos III (Ayuda de incentivación a la participación en proyectos del Espacio Europeo de Investigación) and the Spanish Ministry of Education and Science (A107190024). CG and QB were supported by a grant from the Spanish Ministry of Health (Contrato post-Formación Sanitaria Especializada, Fondo de Investigaciones Sanitarias, Instituto de Salud Carlos III, CM04/00028 and CM05/00134, respectively), MNM by a PhD Scholarship from Fundació Marfà, AM by a Miguel Servet grant from the Instituto de Salud Carlos III (CP-04/00220), and CD by a Ramón y Cajal grant from the Spanish Ministry of Science and Innovation (RYC-2008-02631). The Manhiça Health Research Centre receives core funding from the Spanish Agency for International Cooperation and Development (AECID). The funders had no role in study design, data collection and analysis, or preparation of the manuscript.

\section{Author details}

${ }^{1}$ Centro de Investigação em Saúde de Manhiça (CISM), Maputo, Mozambique. ${ }^{2}$ Barcelona Centre for International Health Research (CRESIB, Hospital Clínic - Universitat de Barcelona), Barcelona, Catalonia, Spain. ${ }^{3}$ CIBER Epidemiología y Salud Pública (CIBERESP), Madrid, Spain. ${ }^{4}$ International Centre for Genetic Engineering and Biotechnology (ICGEB), New Delhi, India.

Received: 9 December 2013 Accepted: 22 March 2014

Published: 27 March 2014

\section{References}

1. WHO: World Malaria Report. Geneva: World Health Organization; 2012:238.

2. Doolan DL, Dobaño C, Baird JK: Acquired immunity to malaria. Clin Microbiol Rev 2009, 22:13-36.

3. Stanisic DI, Richards JS, McCallum FJ, Michon P, King CL, Schoepflin S, Gilson PR, Murphy VJ, Anders RF, Mueller I, Beeson JG: Immunoglobulin G subclass-specific responses against Plasmodium falciparum merozoite antigens are associated with control of parasitemia and protection from symptomatic illness. Infect Immun 2009, 77:1165-1174.

4. Greenhouse B, Ho B, Hubbard A, Njama-Meya D, Narum DL, Lanar DE, Dutta S, Rosenthal PJ, Dorsey G, John CC: Antibodies to Plasmodium falciparum antigens predict a higher risk of malaria but protection from symptoms once parasitemic. J Infect Dis 2011, 204:19-26.

5. Ofori MF, Dodoo D, Staalsoe T, Kurtzhals JAL, Koram K, Theander TG, Akanmori BD, Hviid L: Malaria-induced acquisition of antibodies to
Plasmodium falciparum variant surface antigens. Infect Immun 2002, 70:2982-2988.

6. Nielsen MA, Staalsoe T, Kurtzhals JAL, Goka BQ, Dodoo D, Alifrangis M, Theander TG, Akanmori BD, Hviid L: Plasmodium falciparum variant surface antigen expression varies between isolates causing severe and nonsevere malaria and is modified by acquired immunity. J Immunol 2002, 168:3444-3450.

7. Richards JS, Beeson JG: The future for blood-stage vaccines against malaria. Immunol Cell Biol 2009, 87:377-390.

8. Chen $\mathrm{Q}$, Schlichtherle M, Wahlgren M: Molecular aspects of severe malaria. Clin Microbiol Rewiews 2000, 13:439-450.

9. Osier FHA, Fegan G, Polley SD, Murungi L, Verra F, Tetteh KKA, Lowe B, Mwangi T, Bull PC, Thomas AW, Cavanagh DR, McBride JS, Lanar DE, Mackinnon MJ, Conway DJ, Marsh K: Breadth and magnitude of antibody responses to multiple Plasmodium falciparum merozoite antigens are associated with protection from clinical malaria. Infect Immun 2008, 76:2240-2248.

10. Oeuvray C, Bouharoun-Tayoun H, Gras-Masse H, Bottius E, Kaidoh T, Aikawa M, Filgueira MC, Tartar A, Druilhe P: Merozoite surface protein-3: a malaria protein inducing antibodies that promote Plasmodium falciparum killing by cooperation with blood monocytes. Blood 1994, 84:1594-1602.

11. Roussilhon C, Oeuvray C, Müller-Graf C, Tall A, Rogier C, Trape J-F, Theisen $M$, Balde $A$, Pérignon $J$ - $L$, Druilhe $P$ : Long-term clinical protection from falciparum malaria is strongly associated with lgG3 antibodies to merozoite surface protein 3. PLoS Med 2007, 4:e320.

12. Spring MD, Cummings JF, Ockenhouse CF, Dutta S, Reidler R, Cohen J, Heppner DG: Phase 1/2a study of the malaria vaccine candidate apical membrane antigen-1 (AMA-1) administered in adjuvant system AS01B or AS02A. PLoS One 2009, 4:e5254.

13. McCallum FJ, Persson KEM, Mugyenyi CK, Fowkes FJI, Simpson JA, Richards JS, Williams TN, Marsh K, Beeson JG: Acquisition of growth-inhibitory antibodies against blood-stage Plasmodium falciparum. PLOS One 2008, 3:e3571.

14. Cowman AF, Crabb BS: Invasion of red blood cells by malaria parasites. Cell 2006, 124:755-766.

15. Verra F, Chokejindachai W, Weedall GD, Polley SD, Mwangi TW, Marsh K, Conway DJ: Contrasting signatures of selection on the Plasmodium falciparum erythrocyte binding antigen gene family. Mol Biochem Parasitol 2006, 149:182-90.

16. Fowkes FJl, Richards JS, Simpson JA, Beeson JG: The relationship between anti-merozoite antibodies and incidence of Plasmodium falciparum malaria: A systematic review and meta-analysis. PLoS Med 2010, 7:e1000218.

17. Bull PC, Lowe BS, Kortok M, Molyneux CS, Newbold Cl, Marsh K: Parasite antigens on the infected red cell surface are targets for naturally acquired immunity to malaria. Nat Med 1998, 4:358-360.

18. Marsh K, Howard RJ: Antigens induced on erythrocytes by Plasmodium falciparum: expression of diverse and conserved determinants. Science 1986, 231:150-153

19. Abdel-Latif MS, Khattab A, Lindenthal C, Kremsner PG, Klinkert M-Q: Recognition of variant rifin antigens by human antibodies induced during natural Plasmodium falciparum infections. Infect Immun 2002, 70:7013-7021

20. Baruch DI, Gormely JA, Ma C, Howard RJ, Pasloske BL: Plasmodium falciparum erythrocyte membrane protein 1 is a parasitized erythrocyte receptor for adherence to $\mathrm{CD} 36$, thrombospondin, and intercellular adhesion molecule 1. Proc Natl Acad Sci U S A 1996, 93:3497-3502.

21. Egan AF, Burghaus $P$, Druilhe $P$, Holder AA, Riley EM: Human antibodies to the $19 \mathrm{kDa}$ C-terminal fragment of Plasmodium falciparum merozoite surface protein 1 inhibit parasite growth in vitro. Parasite Immunol 1999, 21:133-139.

22. Vestergaard LS, Lusingu JP, Nielsen MA, Mmbando BP, Dodoo D, Akanmori $B D$, Alifrangis M, Bygbjerg IC, Lemnge MM, Staalsoe T, Hviid L, Theander TG: Differences in human antibody reactivity to Plasmodium falciparum variant surface antigens are dependent on age and malaria transmission intensity in northeastern Tanzania. Infect Immun 2008, 76:2706-2714.

23. Baird JK: Age-dependent characteristics of protection v. susceptibility to Plasmodium falciparum. Ann Trop Med Parasitol 1998, 92:367-390.

24. Schellenberg D, Menendez C, Kahigwa E, Aponte J, Vidal J, Tanner M, Mshinda $\mathrm{H}$, Alonso $\mathrm{P}$ : Intermittent treatment for malaria and anaemia control at time of routine vaccinations in Tanzanian infants: a randomised, placebo-controlled trial. Lancet 2001, 357:1471-1477. 
25. Alonso PL, Smith T, Schellenberg JR, Masanja H, Mwankusye S, Urassa H: Bastos de Azevedo I, Chongela J, Kobero S, Menendez C: Randomised trial of efficacy of SPf66 vaccine against Plasmodium falciparum malaria in children in southern Tanzania. Lancet 1994, 344:1175-1181.

26. Guinovart C, Dobaño C, Bassat Q, Nhabomba A, Quintó L, Manaca MN, Aguilar R, Rodríguez MH, Barbosa A, Aponte JJ, Mayor AG, Renom M, Moraleda C, Roberts DJ, Schwarzer E, Le Souëf PN, Schofield L, Chitnis CE, Doolan DL, Alonso PL: The role of age and exposure to Plasmodium falciparum in the rate of acquisition of naturally acquired immunity: a randomized controlled trial. PLoS One 2012, 7:e32362.

27. Alonso P, Aponte J, Gomez-Olive X, Nhacolo A, Thomson R, Macete E, Abacassamo F, Ventura PJ, Dgedge M: Manhiça demographic surveillance system. In Indepth Monogr. Volume 1. Maputo: Centro de Investigação em Saúde de Manhiça; 2002:1-15.

28. Sacarlal J, Aponte JJ, Aide P, Mandomando I, Bassat Q, Guinovart C, Leach A, Milman J, Macete E, Espasa M, Ofori-Anyinam O, Thonnard J, Corachan S, Dubois M-C, Lievens M, Dubovsky F, Ballou WR, Cohen J, Alonso PL: Safety of the RTS, S/AS02A malaria vaccine in Mozambican children during a Phase Ilb trial. Vaccine 2008, 26:174-84.

29. Quelhas D, Jiménez A, Quintó L, Serra-Casas E, Mayor A, Cisteró P, Puyol L, Wilson DW, Richards JS, Nhampossa T, Macete E, Aide P, Mandomando I, Sanz S, Aponte JJ, Alonso PL, Beeson JG, Menéndez C, Dobaño C: IgG against Plasmodium falciparum variant surface antigens and growth inhibitory antibodies in Mozambican children receiving intermittent preventive treatment with sulfadoxine-pyrimethamine. Immunobiology 2011, 216:793-802.

30. Mayor A, Rovira-Vallbona E, Machevo S, Bassat Q, Aguilar R, Quintó L, Jiménez A, Sigauque B, Dobaño C, Kumar S, Singh B, Gupta P, Chauhan VS, Chitnis CE, Alonso PL, Menéndez C: Parity and placental infection affect antibody responses against Plasmodium falciparum during pregnancy. Infect Immun 2011, 79:1654-1659.

31. Trager $W$, Jensen JB: Human malaria parasites in continuous culture. Science 1976, 193:673-675.

32. Quelhas D, Puyol L, Quintó L, Serra-Casas E, Nhampossa T, Macete E, Aide P, Mayor A, Mandomando I, Sanz S, Aponte JJ, Chauhan VS, Chitnis CE, Alonso PL, Menéndez C, Dobaño C: Impact of intermittent preventive treatment with sulfadoxine-pyrimethamine on antibody responses to erythrocytic-stage Plasmodium falciparum antigens in infants in Mozambique. Clin Vaccine Immunol 2008, 15:1282-1291.

33. Mayor A, Serra-Casas E, Bardají A, Sanz S, Puyol L, Cisteró P, Sigauque B, Mandomando I, Aponte JJ, Alonso PL, Menéndez C: Sub-microscopic infections and long-term recrudescence of Plasmodium falciparum in Mozambican pregnant women. Malar J 2009, 8:9.

34. Quelhas D, Puyol L, Quintó L, Nhampossa T, Serra-Casas E, Macete E, Aide P, Sanz S, Aponte JJ, Doolan DL, Alonso PL, Menéndez C, Dobaño C: Intermittent preventive treatment with sulfadoxine-pyrimethamine does not modify plasma cytokines and chemokines or intracellular cytokine responses to Plasmodium falciparum in Mozambican children. BMC Immunol 2012, 13:5

35. Dobaño C, Quelhas D, Quintó L, Puyol L, Serra-Casas E, Mayor A, Nhampossa T, Macete E, Aide P, Mandomando I, Sanz S, Puniya SK, Singh B, Gupta P, Bhattacharya A, Chauhan VS, Aponte JJ, Chitnis CE, Alonso PL, Menéndez C: Age-dependent lgG subclass responses to Plasmodium falciparum EBA-175 are differentially associated with incidence of malaria in Mozambican children. Clin Vaccine Immunol 2012, 19:157-66.

36. Serra-Casas E, Menéndez C, Bardají A, Quintó L, Dobaño C, Sigauque B, Jiménez A, Mandomando I, Chauhan VS, Chitnis CE, Alonso PL, Mayor A: The effect of intermittent preventive treatment during pregnancy on malarial antibodies depends on HIV status and is not associated with poor delivery outcomes. J Infect Dis 2010, 201:123-31.

37. Gray JC, Corran PH, Mangia E, Gaunt MW, Li Q, Tetteh KKA, Polley SD, Conway DJ, Holder AA, Bacarese-Hamilton T, Riley EM, Crisanti A: Profiling the antibody immune response against blood stage malaria vaccine candidates. Clin Chem 2007, 53:1244-1253.

38. Polley SD, Mwangi T, Kocken CHM, Thomas AW, Dutta S, Lanar DE, Remarque E, Ross A, Williams TN, Mwambingu G, Lowe B, Conway DJ, Marsh K: Human antibodies to recombinant protein constructs of Plasmodium falciparum Apical Membrane Antigen 1 (AMA1) and their associations with protection from malaria. Vaccine 2004, 23:718-728.

39. Ngoundou-Landji J, Nwuba Rl, Anumudu Cl, Odaibo AB, Matondo Maya WD, Awobode HO, Okafor CM, Morenikeji OA, Asinobi A, Nwagwu M,
Holder AA, Ntoumi F: Fine specificity of anti-MSP119 antibodies and multiplicity of Plasmodium falciparum merozoite surface protein 1 types in individuals in Nigeria with sub-microscopic infection. Malar J 2010, 9:287.

40. McCarra MB, Ayodo G, Sumba PO, Kazura JW, Moormann AM, Narum DL, John CC: Antibodies to Plasmodium falciparum erythrocyte-binding antigen-175 are associated with protection from clinical malaria. Pediatr Infect Dis J 2011, 30(12):1037-1042.

41. Dodoo D, Aikins A, Kusi KA, Lamptey H, Remarque E, Milligan P, Bosomprah S, Chilengi R, Osei YD, Akanmori BD, Theisen M: Cohort study of the association of antibody levels to AMA1, MSP119, MSP3 and GLURP with protection from clinical malaria in Ghanaian children. Malar J 2008, 7:142.

42. Campo JJ, Dobaño C, Sacarlal J, Guinovart C, Mayor A, Angov E, Dutta S, Chitnis C, Macete E, Aponte JJ, Alonso PL: Impact of the RTS S malaria vaccine candidate on naturally acquired antibody responses to multiple asexual blood stage antigens. PLoS One 2011, 6:e25779.

doi:10.1186/1475-2875-13-121

Cite this article as: Nhabomba et al.: Impact of age of first exposure to Plasmodium falciparum on antibody responses to malaria in children: a randomized, controlled trial in Mozambique. Malaria Journal 2014 13:121.

\section{Submit your next manuscript to BioMed Central and take full advantage of:}

- Convenient online submission

- Thorough peer review

- No space constraints or color figure charges

- Immediate publication on acceptance

- Inclusion in PubMed, CAS, Scopus and Google Scholar

- Research which is freely available for redistribution

Submit your manuscript at www.biomedcentral.com/submit
C Biomed Central 